\title{
Magnetoelectrics: Three Centuries of Research Heading Towards the 4.0 Industrial Revolution
}

\author{
Nélson Pereira ${ }^{1,2}$, Ana Catarina Lima ${ }^{1,3}\left[\right.$, Senentxu Lanceros-Mendez ${ }^{4,5, *(1)}$ \\ and Pedro Martins 1,6,*(D) \\ 1 Centro/Departamento de Física, Universidade do Minho, 4710-057 Braga, Portugal; \\ nmmsp.18@gmail.com (N.P.); anacatari18@gmail.com (A.C.L.) \\ 2 Algoritmi Center, Minho University, 4800-058 Guimarães, Portugal \\ 3 INL-International Iberian Nanotechnology Laboratory, 4715-330 Braga, Portugal \\ 4 BCMaterials, Basque Center for Materials, Applications and Nanostructures, Universidad del País \\ Vasco/Euskal Herriko Unibertsitatea, Science Park, 48940 Leioa, Spain \\ 5 Basque Foundation for Science (Ikerbasque), 48013 Bilbao, Spain \\ 6 IB-S Institute of Science and Innovation for Bio-sustainability, Universidade do Minho, \\ 4710-057 Braga, Portugal \\ * Correspondence: senentxu.lanceros@bcmaterials.net (S.L.-M.); pmartins@fisica.uminho.pt (P.M.)
}

Received: 21 July 2020; Accepted: 24 August 2020; Published: 11 September 2020

\begin{abstract}
Magnetoelectric (ME) materials composed of magnetostrictive and piezoelectric phases have been the subject of decades of research due to their versatility and unique capability to couple the magnetic and electric properties of the matter. While these materials are often studied from a fundamental point of view, the 4.0 revolution (automation of traditional manufacturing and industrial practices, using modern smart technology) and the Internet of Things (IoT) context allows the perfect conditions for this type of materials being effectively/finally implemented in a variety of advanced applications. This review starts in the era of Rontgen and Curie and ends up in the present day, highlighting challenges/directions for the time to come. The main materials, configurations, ME coefficients, and processing techniques are reported.
\end{abstract}

Keywords: magnetoelectric; piezoelectric; magnetostrictive; multiferroic; IoT; 4.0 industrial revolution

\section{Introduction}

Multiferroic materials are formed by at least two ferroic orders: a ferroelectric order where spontaneous and stable polarization can be switched hysteretically by an applied electric field; a ferromagnetic order where spontaneous and stable magnetization can be switched hysteretically by an applied magnetic field or ferroelastic order where spontaneous and stable deformation can be switched hysteretically by an applied stress [1]. The interaction between different ferroic orders can produce effects such as the magnetoelectric (ME) one schematically represented in Figure 1.

Such a ME response is reflected in the appearance of an electric polarization variation when applying an external magnetic field, or in the induced magnetization variation under an external electric field [2]. The initial studies regarding the ME effect by Rontgen in 1888 [3] and Curie in 1894 [4] reported that a moving dielectric became magnetized when placed in a magnetic field and the possibility of intrinsic linear ME behaviour of crystals based on symmetry considerations, respectively. After those considerations, the ME concept started to get increasing attention. The term "magnetoelectric" was introduced by Debye in 1926, after the first failed attempts to experimentally demonstrate the ME effect. Three decades later, in 1959, Dzyaloshinkii reported two evidences of the ME effect: (i) that an electric field induced magnetization on $\mathrm{Cr}_{2} \mathrm{O}_{3}$ and (ii) a magnetic field induced polarization in the same $\mathrm{Cr}_{2} \mathrm{O}_{3}[5,6]$. 


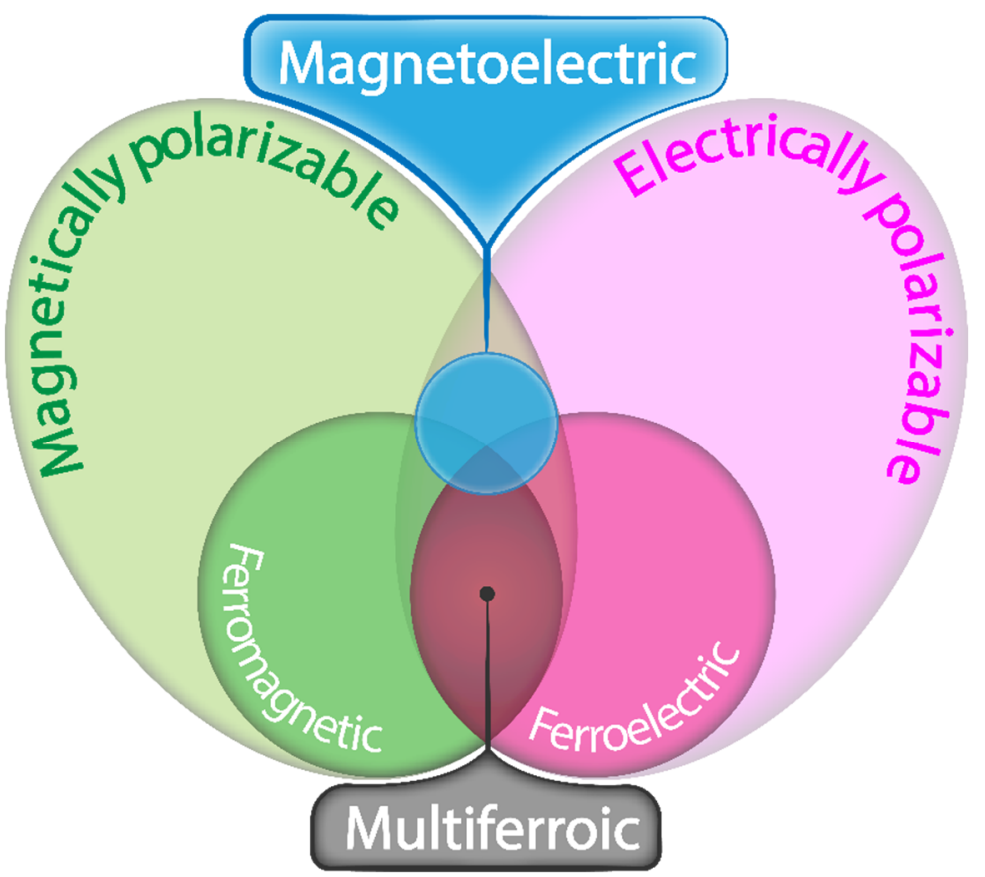

Figure 1. The relation between multiferroic and ME materials, adapted from [1].

After such observations of the ME effect in $\mathrm{Cr}_{2} \mathrm{O}_{3}$, interest in the ME coupling effect declined from some years due to the fact that the low magnitude of ME coupling was not enough to allow $\mathrm{ME}$ phase control in devices such as memories or switching devices with magnetic control of the electrical polarization, and vice-versa [7]. The low number of materials displaying ME behaviour also did not support the proposed applications requiring specific physical properties and stability. In particular, the Curie temperature $\left(T_{c}\right)$ was below room temperature and the discrete compositions with limited possibilities for tuning the ME response were some of the Achilles heels in this area. Additionally, there were also limited techniques for the detailed/reproducible study of the ME behaviour [7].

The first ME composite material was produced in the 1970s by combining piezoelectric and ferroelectric $\mathrm{BaTiO}_{3}$ and piezomagnetic and ferromagnetic $\mathrm{CoFe}_{2} \mathrm{O}_{4}$ [8]. Despite the improvements on composites that allowed ME coupling to occur at room-temperature, the ME response was never above $\approx 100 \mathrm{mV} \cdot \mathrm{cm}^{-1} \cdot \mathrm{Oe}^{-1}$, due to inconsistencies in chemical reactions during the sintering process, low resistivity of the magnetostrictive phase, and induced eddy currents by the applied AC voltage. Also, dispersion problems in nanocomposites, mechanical defects limiting the mechanical coupling, and difficult on aligning the electric dipoles were issues still to be solved [7].

Only in the 1990s was interest on the ME effect renewed with the introduction of new ME interactions and degrees of freedom in designing ME compounds, innovative experimental techniques and optimized theoretical tools [9]. The experiments allowing one to tune new parameters, such as stoichiometry and the microstructure of the ME materials were carried out to produce large ME response, orders of magnitude higher than the one in single-phase materials at room temperature [7].

The magnetic and piezoelectric phases in ME composites can be divided based on their connectivity types in (0-3) particulate composite; (2-2) laminate composite and (1-3) fiber/rod composite (Figure 2) [2].

In (0-3) particulate composites, a high concentration of magnetic particles needs to be dispersed into the selected piezoelectric matrix. The properties of the composite can be easily tailored by selecting the constituent phases, the particle sizes, and processing parameters [10]. 
a)

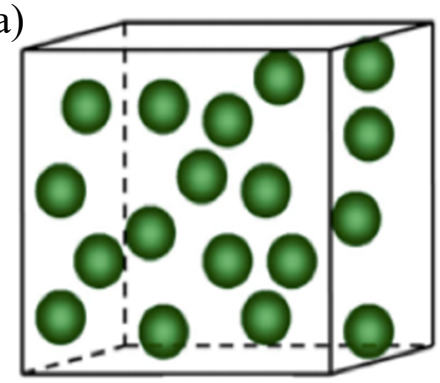

b)

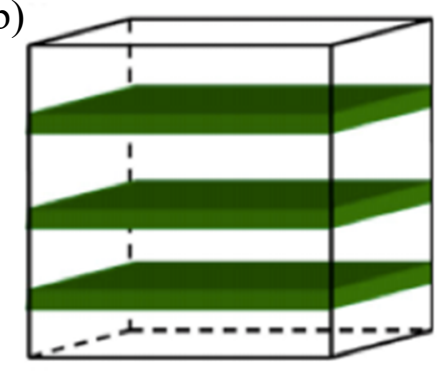

c)

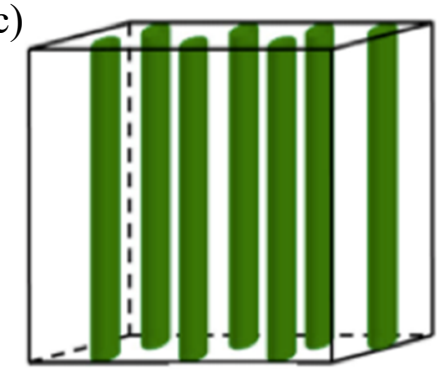

Figure 2. The schematic illustration of three bulk composites with different connectivity: (a) (0-3) particulate composite; (b) (2-2) laminate composite; (c) (1-3) fiber/rod composite. Reproduced with permission from [2].

In (2-2) laminate composites, the piezoelectric and magnetostrictive phases are often joined by a coupling agent, leading to an elimination of the leakage current, resulting on a superior ME performance [11]. Such laminates can be arranged in different shapes and geometries, including discs, squares, rectangles, and rings, with different dimensions. They can be arranged as unimorphs and bimorphs as well as bilayered and multilayered structures [12].

Regarding (1-3) fiber/rod composites, the magnetic phase can also lead to leakage currents during polarization [2], and very few attempts have been made to fabricate this type of bulk ME composite. To overcome this, (1-3) fiber/rod composites typically consist of three phases: PE bulk, magnetostrictive (MS) material and insulating polymers [13].

The first ME using a laminar topology was fabricated in 2001 by sandwiching a Lead zirconate titanate (PZT) disc between two Terfenol-D discs connected with silver epoxy, avoiding the previously reported problems in ME particulate composites, such as low ME response and leakage currents [7]. This laminate achieved a ME coupling coefficient of $4.68 \mathrm{~V} \cdot \mathrm{cm}^{-1} \cdot \mathrm{Oe}^{-1}$ with a $4.2 \mathrm{kOe} \mathrm{DC}$ magnetic field at $1 \mathrm{kHz}$, exceeding the values obtained in ME particulate composites at the time [8].

These approaches and promising findings led to an increase research activity in the subsequent years, being a part of this research focused on substituting the ceramic piezoelectric materials of the ME particulate composites, by insulating piezoelectric polymers to overcome technical problems such as fragility and high dielectric losses, that lead to low output voltages [14].

The polymer-based ME composites strategy offered a new approach for developing new applications with easy production at low temperatures and additive manufacturing capability (inkjet printing and screen printing, among others), tuned mechanical properties for flexible devices, large area applications, low-cost and biocompatible devices [14], suitable for the internet of things (IoT) and Industry 4.0. Such IoT devices demands on optimized performances, low power consumption and integrated applications can be achieved with ME materials (Figure 3).

The main experimental methods for measuring the ME coefficient are the static, quasi-static, dynamic and pulsed dynamic methods. For the dynamic method, the sample is subjected to the action of a superimposed AC field in a variable DC magnetic field, which generates at the ends of the material a voltage response (ME signal) which permits to obtain the ME voltage coefficient $\left(\alpha_{\mathrm{ME}}\right)$ value indirectly through Equation (1):

$$
\alpha_{M E}=\frac{\Delta V}{t \cdot H_{A C}}
$$

where $\Delta V$ is the generated voltage, $t$ the thickness of the piezoelectric material and $H_{A C}$ the intensity of the $A C$ magnetic field. 


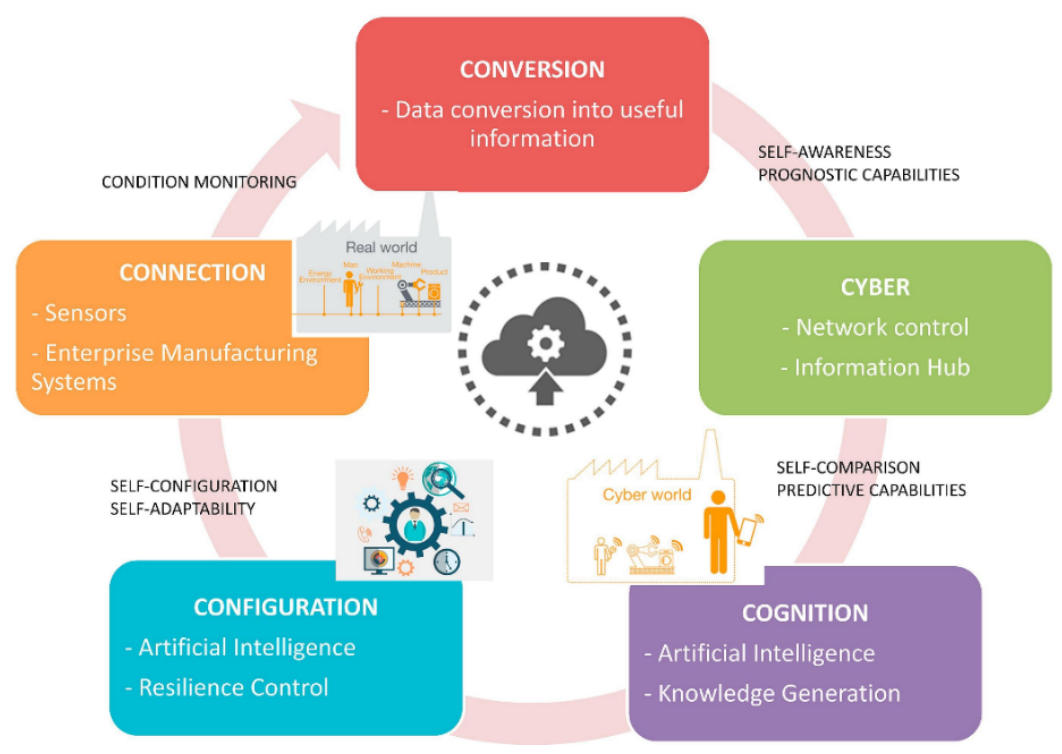

Figure 3. The model for Industry 4.0. Reproduced with permission from [15].

This method had a great reception since it reduces the problems of charge accumulation at the edge of the sample, and for such reason in the most used in the literature [16].

ME systems converting magnetic energy into electrical output (or vice-versa) can increase the productivity and efficiency of resources [17]. Additionally, information and communication technologies allow ME smart products with embedded sensors, actuators, processing units, connected via internet enabling functionalities for monitoring, control, real time optimization and autonomy $[18,19]$.

Thus, the research on ME materials associated with IoT in the industry 4.0 context, taking advantage of the developments achieved over the past years and in both areas (Figure 4), can lead to new applications that enable monitoring and real time optimization and autonomy, by the introduction of self-sensing magnetic sensors and actuators for real time sensing, monitoring and response, enabling at the same time energy harvesting from the environment. Additionally, ME devices make possible to enhance real time communication with better tuned antennas.

This work aims to make a time travel through three centuries, starting in the pioneer studies regarding single-phase $\mathrm{ME}$, until the implementation of ME materials within the 4.0 paradigm, passing by through a discussion concerning the main problems and future perspectives of the ME area.
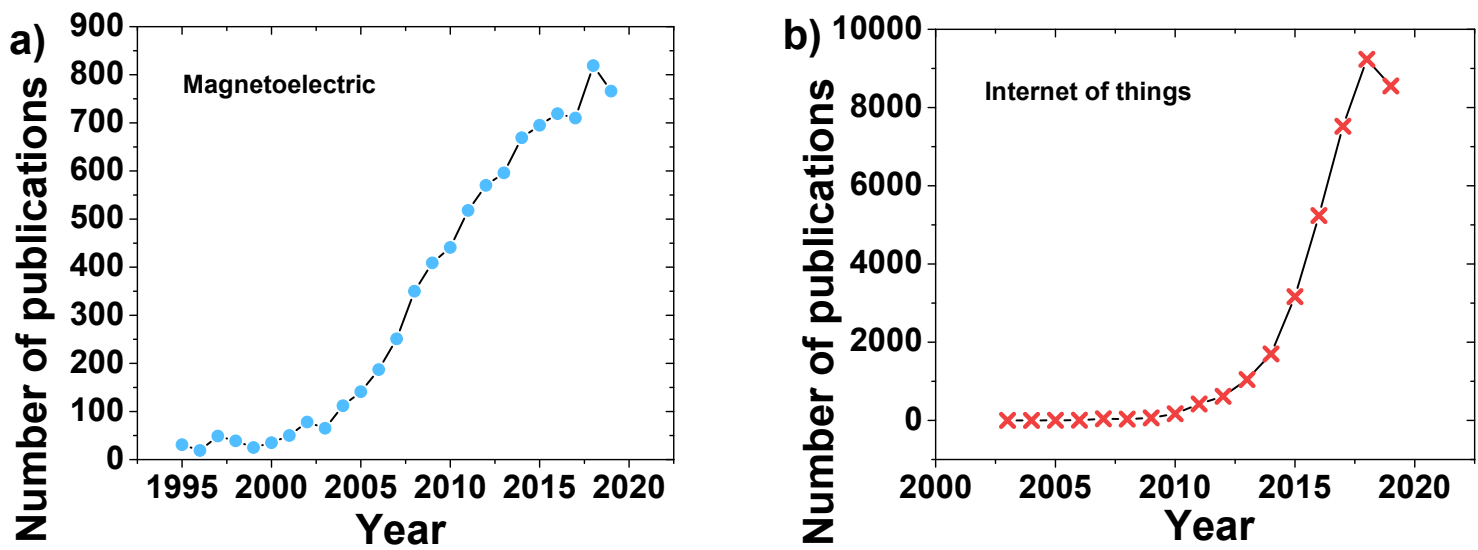

Figure 4. The publications per year according to the Web of Science database (7/2020) with the key words (a) magnetoelectric; and (b) internet of things [20]. 


\section{Single-Phase ME}

As previously shown, single-phase multiferroic materials are characterized by the intrinsic characteristic of presenting at least two ferroic orders [1]. The ME response is observed as an intrinsic effect typically at low temperatures $(<10 \mathrm{~K})$, that can be used for applications in data storage, spintronics or memories [2]. Shalini et al. [21] used a standard solid-state reaction method [22] by taking stoichiometric quantities of $\mathrm{K}_{2} \mathrm{CO}_{3}, \mathrm{Na}_{2} \mathrm{CO}_{3}, \mathrm{Nb}_{2} \mathrm{O}_{5}, \mathrm{Fe}_{2} \mathrm{O}_{3} \mathrm{MnO}_{2}$, mixed in an agate mortar and calcined at $1373.15 \mathrm{~K}$ for two hours, creating the multiferroic ceramic $\mathrm{K}_{0.5} \mathrm{Na}_{0.5}\left[\mathrm{Nb}_{1-\mathrm{x}} \mathrm{Fe}_{\mathrm{x} / 2} \mathrm{Mn}_{\mathrm{x} / 2}\right] \mathrm{O}_{3}$ $(x=0.025,0.05,0.075,0.10)$ [21]. This work verifies the behaviour in alkali niobate-based ferroelectric called potassium sodium niobite $(\mathrm{KNN})$, a lead-free ceramic through the substitution of transition elements. This multiferroic ceramic material achieved a longitudinal ME coefficient $\left(\alpha_{\mathrm{ME}}\right)$ value of $3.45 \mathrm{mV} \cdot \mathrm{cm}^{-1} \cdot \mathrm{Oe}^{-1}$ with an $\mathrm{H}_{\mathrm{DC}}$ of $1000 \mathrm{Oe}$ and $\mathrm{H}_{\mathrm{AC}}$ of 60 Oe [21].

Pikula et al. [23] prepared a $\mathrm{Bi}_{0.5} \mathrm{Nd}_{0.5} \mathrm{FeO}_{3}$ solid solution using a standard solid-state reaction method. The stoichiometric mixture of oxide powders was grinded in a planetary ball mill for $24 \mathrm{~h}$. The obtained mixture was consolidated into pellets and calcined at $1023 \mathrm{~K}$ for $10 \mathrm{~h}$. Then, the material was crushed and milled in ethyl alcohol. After drying, the ceramic was again formed into pellets under a pressure of $60 \mathrm{MPa}$ and then sintered at $1273 \mathrm{~K}$ during $24 \mathrm{~h}$ [23]. The samples were evaluated in a frequency interval from $100 \mathrm{~Hz}$ to $10 \mathrm{kHz}$ with a applied $\mathrm{H}_{\mathrm{DC}}$ of $0.9 \mathrm{kOe}$, achieving a maxim ME coefficient of $0.46 \mathrm{mV} \cdot \mathrm{cm}^{-1} \cdot \mathrm{Oe}^{-1}$ at $10 \mathrm{kHz}$ (Figure 5) [23].
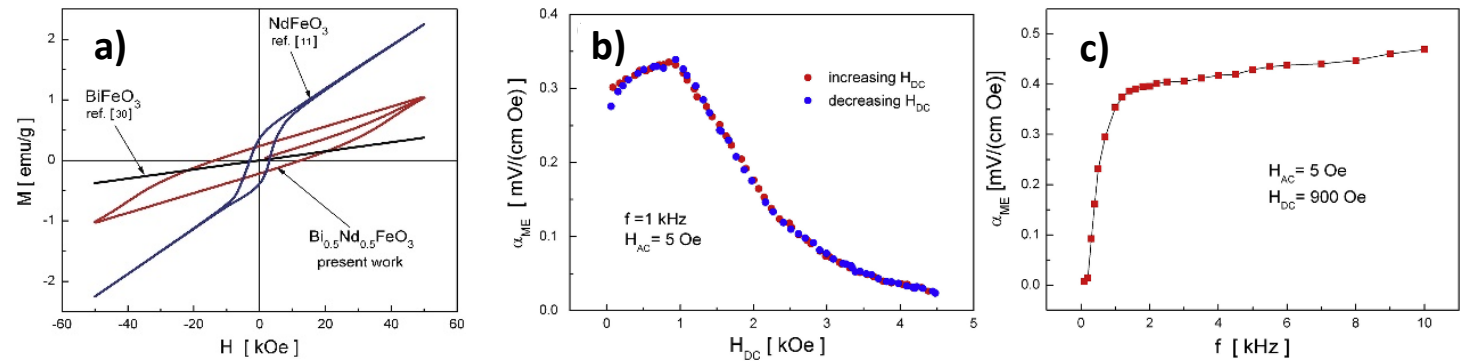

Figure 5. (a) Magnetic field dependence of the magnetization for the $\mathrm{Bi}_{0.5} \mathrm{Nd}_{0.5} \mathrm{FeO}_{3}$ solid solution. ME coupling coefficient variation with: (b) static magnetic field $\mathrm{H}_{\mathrm{DC}}$ and (c) frequency $\mathrm{f}$ of sinusoidal magnetic field $\mathrm{H}_{\mathrm{AC}}$ for $\mathrm{Bi}_{0.5} \mathrm{Nd}_{0.5} \mathrm{FeO}_{3}$ sample. Reproduced with permission from [23].

Based on a similar procedure, Dabas et al. [24] reported a $\mathrm{Mn}$-doped $\mathrm{BiFeO}_{3}$ ceramic. The material was prepared in the required stoichiometric proportion and ground in an agate pestle and mortar, mixed in an acetone medium. This mixture was ground until the acetone dried off, then transferred to a crucible for calcination at $973.15 \mathrm{~K}$ for $7 \mathrm{~h}$. The mixture was pressed in a hydraulic press to obtain pellets of $10 \mathrm{~mm}$ of diameter by $1 \mathrm{~mm}$ of thickness. As a final step the pellets along with the powder mixture were sintered at $1093.15 \mathrm{~K}$ for $9 \mathrm{~h}$, producing samples with 1,3 and 5 molar percentage of Mn [24]. The ME coefficient of the samples with $1 \% \mathrm{Mn}$ and 3\% Mn is almost constant due to low amount of $\mathrm{Mn}$, but in the $5 \% \mathrm{Mn}$ one, a variation is observed for magnetic fields larger than $2000 \mathrm{Oe}$, leading to ME coefficient of $3.36584 \mathrm{mV} \cdot \mathrm{cm}^{-1} \cdot \mathrm{Oe}^{-1}$ at $2696 \mathrm{Oe}$, higher than the one for $1 \%$ $\mathrm{Mn}\left(\approx 0.170 \mathrm{mV} \cdot \mathrm{cm}^{-1} \cdot \mathrm{Oe}^{-1}\right.$ at $\left.2993 \mathrm{Oe}\right)$ and $3 \% \mathrm{Mn}\left(0.67 \mathrm{mV} \cdot \mathrm{cm}^{-1} \cdot \mathrm{Oe}^{-1}\right.$ at $\left.2792 \mathrm{Oe}\right)$ samples [24]. Kumari et al. [25] developed a polycrystalline thin film by PLD of $\mathrm{BaZr}_{0.05}\left(\mathrm{FexTi}_{1-3 \mathrm{x} / 4}\right)_{0.95} \mathrm{O}_{3}$ grown on $\mathrm{Pt} / \mathrm{TiO}_{2} / \mathrm{SiO}_{2} / \mathrm{Si}$ substrate (Figure $6 \mathrm{a}$ )). The $\mathrm{ME}$ coefficient at room temperature was $\approx 165 \mathrm{mV} \cdot \mathrm{cm}^{-1} \cdot \mathrm{Oe}^{-1}$ at 900 Oe for the $x=0.015$ sample, Figure 6b) [25]. Joginder et al. [26] synthesized polycrystalline single phase $\mathrm{Bi}_{4-\mathrm{x}} \mathrm{Sm}_{\mathrm{x}} \mathrm{Ti}_{3-\mathrm{x}} \mathrm{Fe}_{\mathrm{x}} \mathrm{O}_{12 \pm \delta}(0 \leq \mathrm{x} \leq 0.3)$ ceramics with a room temperature ME coefficient of $0.84 \mathrm{mV} \cdot \mathrm{cm}^{-1} \cdot \mathrm{Oe}^{-1}$ for $\mathrm{x}=0.3$ at $993 \mathrm{~Hz}$ with an applied AC field of $3 \mathrm{Oe}$, Figure $6 \mathrm{c}$ ). The ME coupling appears through stress/strain mediated interaction between electric and magnetic sub-lattices [26].

Liu et al. [27] reported an effective ME coupling in cubic ferrimagnetic spinel $\mathrm{LiFe}_{5} \mathrm{O}_{8}$, showing a hysteretic ME signal at room temperature [27]. The $\mathrm{LiFe}_{5} \mathrm{O}_{8}$ powders, $\alpha-\mathrm{Fe}_{2} \mathrm{O}_{3}$ and $\mathrm{Li}_{2} \mathrm{CO}_{3}$ were milled and heated at $1073.15 \mathrm{~K}$ for $5 \mathrm{~h}$. The prepared powder was grounded and pressed into pellets 
with 6 weight percentage (wt.\%) polyvinyl alcohol as binder, then sintered at $1223.15 \mathrm{~K}$ for $5 \mathrm{~h}$, and coated with silver electrodes. This work demonstrated a maximum ME coefficient of $2 \mathrm{mV} \cdot \mathrm{cm}^{-1} \cdot \mathrm{Oe}^{-1}$ at a temperature of $120 \mathrm{~K}$ [27].
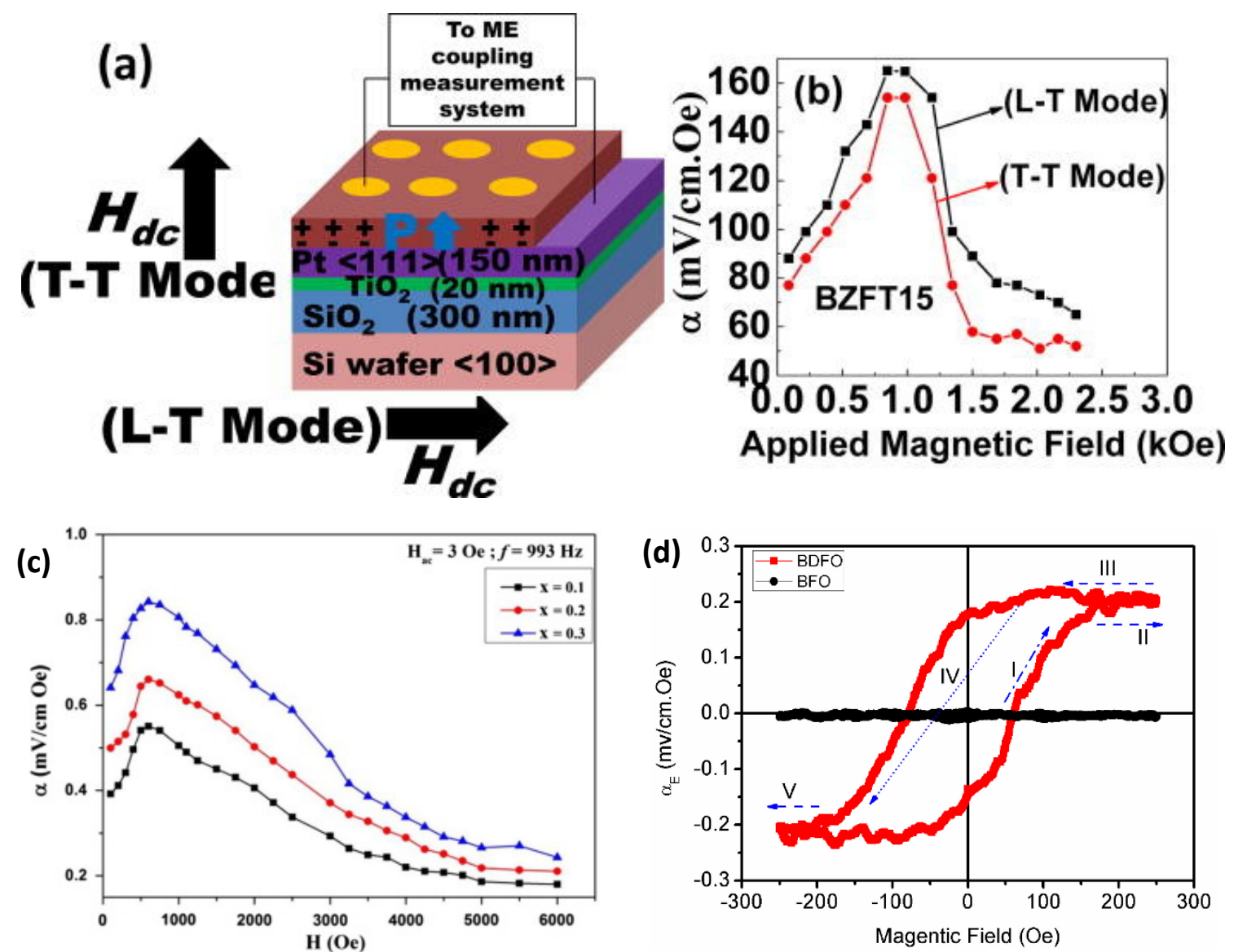

Figure 6. (a) The schematic representation of the experimental conditions; and (b) M-E coupling coefficient versus applied magnetic field measured in both in-plane magnetized-out of plane polarized configuration (L-T) and out of plane magnetized-out of plane polarized (T-T) modes. Reproduced with permission from [25]. (c) $\mathrm{ME}$ coefficient for a $\mathrm{H}_{\mathrm{AC}}=3$ Oe at $993 \mathrm{~Hz}$ [26]. (d) MEP (H) hysteresis loops displayed at $300 \mathrm{~K}$, showing the variations of the ME coefficient as a function of the applied magnetic field for of BDFO (red) and BFO (black). Reproduced with permission from [28].

Ruth et al. [29] reported lead-free Na-deficient single-phase sodium bismuth titanate perovskite $\mathrm{Na} 0.42 \mathrm{Bi} 0.52 \mathrm{Ti}^{2} .005 \mathrm{O}_{3}$ ferroelectrics. The material has shown a self-bias $\mathrm{ME}$ coefficient around $4.18 \mathrm{mV} \cdot \mathrm{cm}^{-1} \cdot \mathrm{Oe}^{-1}\left(\mathrm{H}_{\mathrm{AC}}=1 \mathrm{Oe}\right.$ at $\left.1 \mathrm{kHz}\right)$ at zero DC magnetic field and room temperature [29].

Xue et al. [30] developed a solid solution of single-phase $\mathrm{ME} 00.6 \mathrm{BiFeO}_{3}-0.1 \mathrm{LaFeO}_{3}-0.3 \mathrm{PbFeO}_{2.5}$ based on a mixed oxide solution of $\mathrm{BiFeO}_{3}, \mathrm{LaFeO}_{3}$, and $\mathrm{PbFeO}_{2.5}$. These powders were mixed, ball milled, ground, calcinated and added to polyvinyl alcohol (PVA) $7 \mathrm{wt}$ \% forming pellets. These pellets were sintered at $1223.15 \mathrm{~K}$ for $2 \mathrm{~h}$ then coated with silver electrodes and annealed at $823.15 \mathrm{~K}$ for 30 minutes [30]. The single-phase materials presented a ME coupling of approximately 120 $\mathrm{mV} \cdot \mathrm{cm}^{-1} \cdot \mathrm{Oe}^{-1}[30]$.

Lakshmi et al. [31] synthesized multiferroic ceramic $\mathrm{BiFeO}_{3}$ co-doped with aliovalent $\mathrm{Nb}$, $\mathrm{Mn}$ and Mo at the Fe site by sol-gel [31-33]. $\mathrm{Bi}\left(\mathrm{NO}_{3}\right)_{3} \cdot 5 \mathrm{H}_{2} \mathrm{O}, \mathrm{Fe}\left(\mathrm{NO}_{3}\right)_{3} \cdot 9 \mathrm{H}_{2} \mathrm{O}, \mathrm{Er}\left(\mathrm{NO}_{3}\right)_{3} \cdot \mathrm{H}_{2} \mathrm{O}, \mathrm{Nb}_{2} \mathrm{O}_{5}$, $\mathrm{Mn}\left(\mathrm{NO}_{3}\right)_{2} \cdot \mathrm{H}_{2} \mathrm{O}, \mathrm{MoO}_{6}$ were mixed in distilled water and stirred at $400 \mathrm{rpm}$ until homogenization. Then, the mixture was heated at $353.15 \mathrm{~K}$ on a hot plate until a gel was formed. The gel was converted into powders by auto-combustion, which was then ground and annealed at $873.15 \mathrm{~K}$ for $12 \mathrm{~h}$. The pellets of $8 \mathrm{~mm}$ were prepared from the annealed powders by a hydraulic press under 6 tons pressure and 
sintered at $1073.15 \mathrm{~K}$ for $12 \mathrm{~h}$ [31]. The results of $\mathrm{BiFeO}_{3}$ doped with $\mathrm{Er}$ and $\mathrm{Nb}$ showed a maximum ME coupling coefficient of $0.22 \mathrm{mV} \cdot \mathrm{cm}^{-1} \cdot \mathrm{Oe}^{-1}$ at $13 \mathrm{mT}$ [31].

Luo et al. [20] fabricated $\mathrm{Bi}_{4} \mathrm{SmFeTi}_{3} \mathrm{O}_{15}$ thin films coated on (111) $\mathrm{Pt} / \mathrm{Ti} / \mathrm{SiO}_{2} / \mathrm{Si}$ substrates by the sol-gel method. The precursor solution was constituted by high-purity bismuth nitrate $\left(\mathrm{Bi}\left(\mathrm{NO}_{3}\right)_{3} \cdot 5 \mathrm{H}_{2} \mathrm{O}\right.$ $98 \%)$, samarium oxide $\left(\mathrm{Sm}_{2} \mathrm{O}_{3} 99.9 \%\right)$, iron acetylacetonate $\left(\mathrm{C}_{15} \mathrm{H}_{21} \mathrm{FeO}_{6} 98 \%\right)$ and titanium $n$-butoxide $\mathrm{Ti}\left(\mathrm{C}_{4} \mathrm{H}_{9} \mathrm{O}_{4}\right)(99 \%)$. The ME coefficient observed at room temperature was of $41.16 \mathrm{mV} \cdot \mathrm{cm}^{-1} \cdot \mathrm{Oe}^{-1}$ at $0.9 \mathrm{~T}$ [20]. Zhao et al. [34] developed a room temperature bismuth-layer-structured ferroelectric $\mathrm{Bi}_{5} \mathrm{Ti}_{3} \mathrm{FeO}_{15}$ thin film grown by pulsed laser deposition (PLD) technique [35] on $\mathrm{Pt} / \mathrm{Ti} / \mathrm{SiO}_{2} / \mathrm{Si}$ substrates. The achieved ME coupling at room temperature was of approximately $400 \mathrm{mV} \cdot \mathrm{cm}^{-1} \cdot \mathrm{Oe}^{-1}$ at a zero bias magnetic field $\left(\mathrm{H}_{\mathrm{AC}}=5 \mathrm{Oe}\right)$ [34]. Pan et al. [28] produced a room temperature ME multiferroic based on $\mathrm{BiFeO}_{3}, \mathrm{Bi}_{0.88} \mathrm{Dy}_{0.12} \mathrm{Fe}_{0.97} \mathrm{Ti}_{0.03} \mathrm{O}_{3+\delta}$, prepared via a co-precipitation process with the starting constituents $\mathrm{Bi}\left(\mathrm{NO}_{3}\right)_{3} \cdot 5 \mathrm{H}_{2} \mathrm{O}, \mathrm{Dy}\left(\mathrm{NO}_{3}\right)_{3} \cdot 5 \mathrm{H}_{2} \mathrm{O}$ and $\mathrm{Fe}\left(\mathrm{NO}_{3}\right)_{3} \cdot 9 \mathrm{H}_{2} \mathrm{O}$. An electric field of $80 \mathrm{kV} \cdot \mathrm{cm}^{-1}$ was applied at room temperature to pole the sample and the $\mathrm{ME}$ effect at room temperature reached approximately $0.23 \mathrm{mV} \cdot \mathrm{cm}^{-1} \cdot \mathrm{Oe}^{-1}$ at $250 \mathrm{Oe}$, Figure $6 \mathrm{~d}$ ). The response at low fields could potentially bring $\mathrm{BiFeO}_{3}$ materials closer to practical applications in electronics and spintronics devices were the dipoles can be tuned by a low magnetic field [28].

Yang et al. [36] developed single-phase multiferroic ceramics of $(1-x) \mathrm{BaTiO}_{3}-\mathrm{x} \mathrm{BiFeO}_{3}$ (BT - x $\mathrm{BFO})$ synthesized by solid-solution method that exhibited an $\mathrm{ME}$ coefficient of $0.87 \mathrm{mV} \cdot \mathrm{cm}^{-1} \cdot \mathrm{Oe}^{-1}$, providing a possibility of developing electrically or magnetically tunable thin-film devices. The reported single-phase ME materials, as well as their production technique are summarized in Figure 7, being observed that the ME voltage coefficient can assume a broad range of values, from less than $1 \mathrm{mV} \cdot \mathrm{cm}^{-1} \cdot \mathrm{Oe}^{-1}$ up to almost $1 \mathrm{~V} \cdot \mathrm{cm}^{-1} \cdot \mathrm{Oe}^{-1}$.

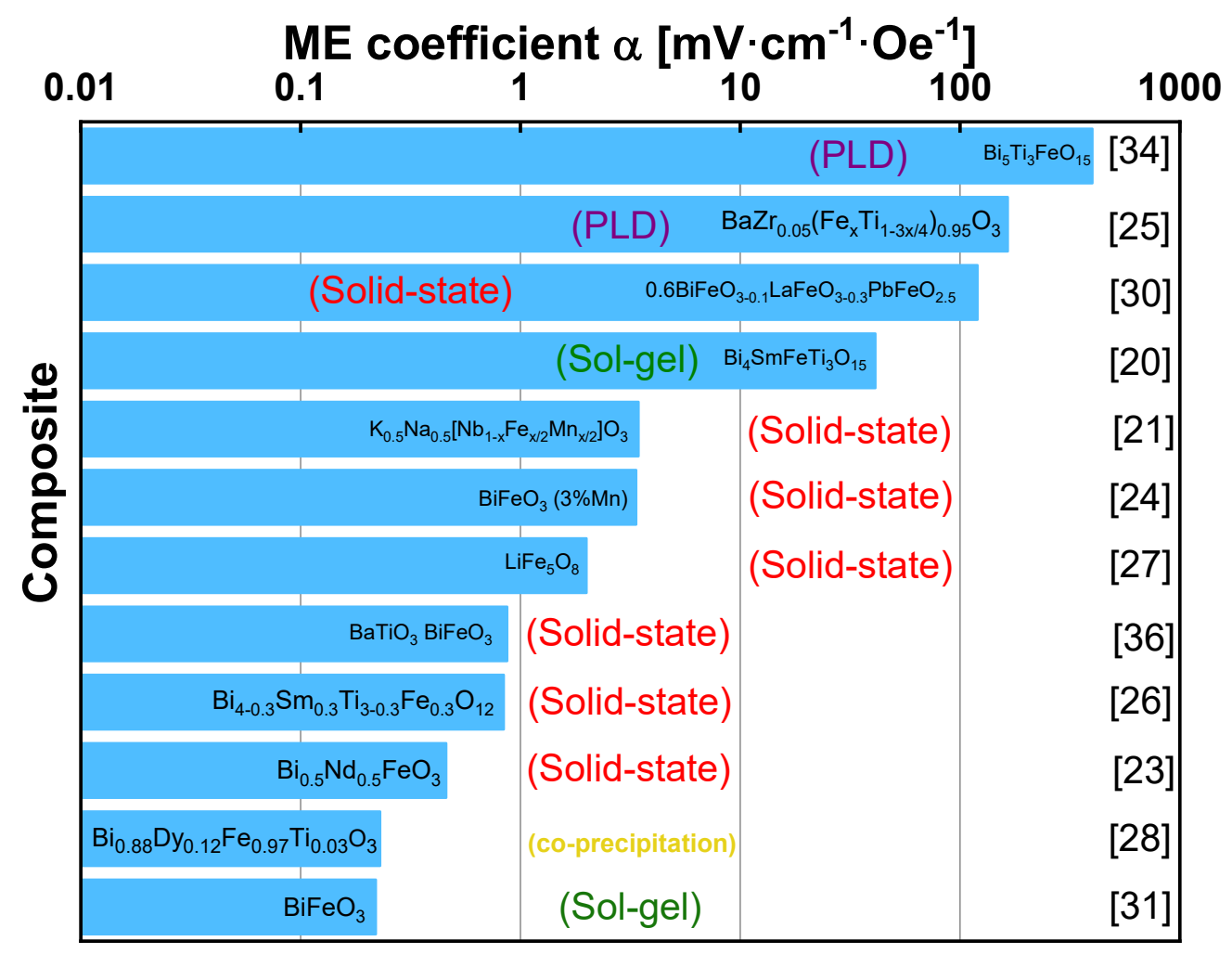

Figure 7. Some representative single-phase materials and their corresponding ME voltage coefficient and fabrication process. 


\section{Ceramic-Based ME}

Ceramic ME composites consist of a ferroelectric oxides and magnetic oxides (mainly ferrites) combination, and they reveal ME coefficients three orders of magnitude higher than ceramic-based ME materials [37]. Improved piezoelectric and ferroelectric properties in ceramics can be achieved through:

- $\quad$ selection of the composition (preferably near morphotropic phase boundary (MPB) or polymorphic phase transition (PPT)) and modification by doping;

- microstructure design via domain engineering and texturing [38].

Lead zirconate titanate (PZT) [39] has been very often used as the ferroelectric phase in ME composites due to its remarkable piezoelectric (PE) effect. At the same time, ferrites are used as magnetostrictive components due to their high magnetostrictive (MS) performance [11], being found reports employing cobalt ferrite $\left(\mathrm{CoFe}_{2} \mathrm{O}_{4}\right)$ [40], nickel ferrite $\left(\mathrm{NiFe}_{2} \mathrm{O}_{4}\right)$ [41] and $\mathrm{Ni} 0.8 \mathrm{Zn} 0.2 \mathrm{Fe}_{2} \mathrm{O}_{4}$ as magnetic phase [42]. Lopatina et al. [43] prepared and investigated PZT/ferrite composites of different connectivity. The highest value of the ME coefficient $\left(110 \mathrm{mV} \cdot \mathrm{cm}^{-1} \cdot \mathrm{Oe}^{-1}\right)$ with the bias magnetic field $\mathrm{H}_{0}=0.9 \mathrm{kOe}$ ) were found in sintered mixtures of PZT powders with ferrite and sliced materials with $35-55$ wt. $\%$ of ferrite.

The main disadvantage of PZT is the presence of lead, which is being replaced by lead-free dielectrics. It is also reported that PZT films exhibit high acoustic loss at high frequency range [44]. For these reasons, studies have been carried out to find lead free materials comparable in terms of properties, such as $\mathrm{BaTiO}_{3}, \mathrm{Na}_{0.5} \mathrm{Bi}_{0.5} \mathrm{TiO}_{3}, \mathrm{~K}_{0.5} \mathrm{Bi}_{0.5} \mathrm{TiO}_{3}$ or $\mathrm{Na}_{0.5} \mathrm{~K}_{0.5} \mathrm{NbO}_{3}$ [45-47].

It should be noted that ferrites may lead to leakage currents that, consequently, can cause deterioration of the composite insulation. This type of material is processed at high temperatures which can lead to a lower ME coefficient than the one that is theoretically predicted, due the inherent preparation problems, such as thermal expansion and atomic interfacial interdiffusion reactions $[48,49]$. Chemical solution processing and novel sintering techniques such as spark-plasma sintering (SPS) and microwave sintering have been employed to produce the particulate ceramic composites [50-52]. Other magnetostrictive materials, such as $\mathrm{Tb}_{(1-\mathrm{x})} \mathrm{Dy}_{\mathrm{x}} \mathrm{Fe}_{2}$ (Terfenol-D) or Metglas are of great interest for practical applications [53].

Duong et al. [54] reported that (2-2) laminate composites with $50 \mathrm{wt} . \% \mathrm{CoFe}_{2} \mathrm{O}_{4}$ and $50 \mathrm{wt} . \%$ of $\mathrm{BaTiO}_{3}$ revealed an enhanced magnetostrictive and piezoelectric coupling compared to the same materials in (0-3) particulate composites, with a ME coefficient of 5.5 and $4.2 \mathrm{mV} \cdot \mathrm{cm}^{-1} \cdot \mathrm{Oe}^{-1}$ for longitudinal and transverse measurements, at the field 2300 and 940 Oe, respectively. Hang et al. [55], also showed that (2-2) laminate composites of BTO/CFO exhibit higher ME coefficients than the (0-3) particulate composite $\left(135 \mathrm{mV} \cdot \mathrm{cm}^{-1} \cdot \mathrm{Oe}^{-1}\right.$ and $35 \mathrm{mV} \cdot \mathrm{cm}^{-1} \cdot \mathrm{Oe}^{-1}$, respectively, at a DC magnetic field of $2600 \mathrm{Oe}$ and a frequency of $1 \mathrm{kHz}$ ), related to the reduction of dielectric losses. Another strategy to reduce ME signal loss is the placement of internal electrodes (e.g., $\mathrm{Ag}, \mathrm{Ni}$, and $\mathrm{Ag}$-Pd) between the PE and MS layers [48,56].

Among the three main connectivities of ME composites, (2-2) laminate structures present the highest ME coefficient due to the use of MS alloys since 2001 [13]. Also, on ceramic-based composites, Terfenol $\mathrm{D}$ has been used due to its ability to combine low frequency operation and high energy density with high magnetostriction (1000 ppm at fields of $5 \mathrm{kOe}$ ) [57]. Both theoretical and experimental results have been reported [58,59] (Figure 8). However, Terfenol-D-based ME composites present low permeability and high saturation field $(700 \mathrm{kA} / \mathrm{m})$, and because of that, it is not appropriate for low magnetic field applications. Recent research on ME composites has been focused on the search for new magnetostrictive materials having balanced soft magnetic and magnetostrictive properties. FeBSiC alloys (Metglass) in the form of amorphous ribbons developed by a fast solidification process, allow for fast magnetization and demagnetization, showing high permeability and low coercivity and saturation field [60]. 

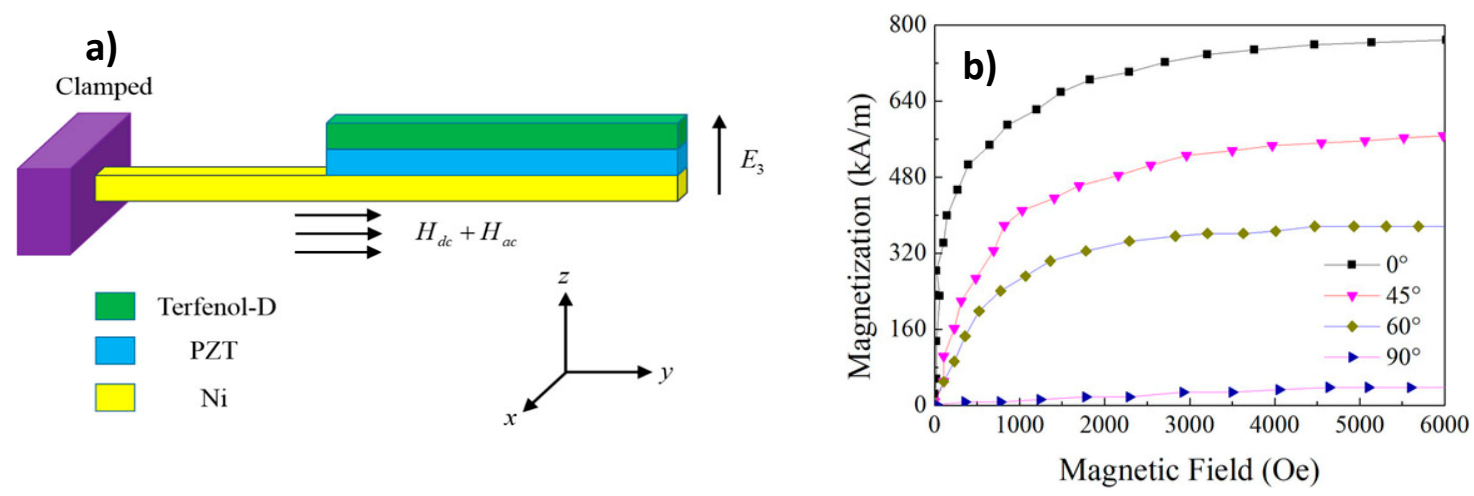

Figure 8. (a) The configuration of laminated Terfenol-D/PZT/Ni composite cantilever; (b) magnetization of Terfenol-D with bias field at different orientation angles. Reproduced with permission from [56].

Amirov et al. [61] proposed a new approach for a ME sandwich structure comprising glass-coated amorphous $\mathrm{Fe}_{77.5} \mathrm{~B}_{15} \mathrm{Si}_{7.5}$ microwires as magnetostrictive layer and PZT as piezoelectric phase with a reported ME coefficient of $100 \mathrm{mV} \cdot \mathrm{cm}^{-1} \cdot \mathrm{Oe}^{-1}$ (Figure 9). This maximum ME response was observed in weak magnetic fields about $3 \mathrm{Oe}$ at electromechanical resonance conditions $(50-60 \mathrm{~Hz})$. The authors stated that this approach can be used for the design of self-biased ME composites that provide large ME coupling under an external AC magnetic field in the absence of a DC magnetic field. Greve, et al. [62] fabricated thin film ME (2-2) composites consisting of aluminum nitride (AlN) and amorphous $\left(\mathrm{Fe}_{90} \mathrm{Co}_{10}\right)_{78} \mathrm{Si}_{12} \mathrm{~B}_{10}$ layers by magnetron sputtering on $\mathrm{Si}(100)$ substrates.
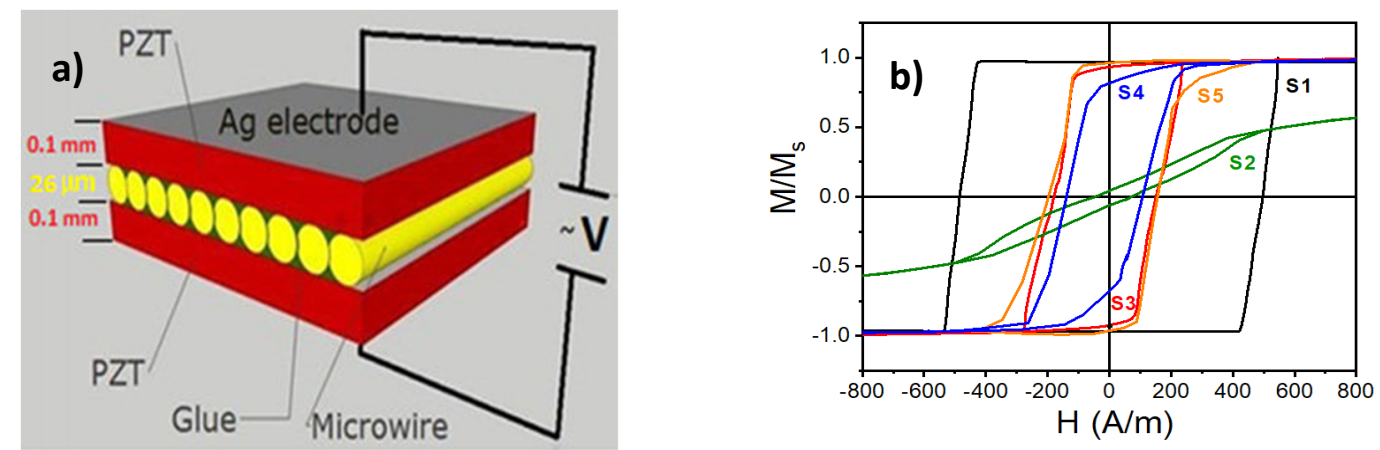

Figure 9. (a) The sketch of the structure of ME composites with microwires; (b) Hysteresis loops of individual microwires with composition of $\mathrm{Fe}_{77.5} \mathrm{~B}_{15} \mathrm{Si}_{7.5}$ in as-cast state (S1) and after different treatments (S2-S5: As-cast and then annealed (S2); As-cast and glass-coat removed (S3); As-cast, annealed, and then glass-coat removed (S4); As-cast, glass-coat removed, and then annealed) [61].

Upon magnetic field annealing an exceptionally high ME coefficient of $737 \mathrm{~V} \cdot \mathrm{cm}^{-1 \cdot} \mathrm{Oe}^{-1}$ at the mechanical resonance of $753 \mathrm{~Hz}$ and $3.1 \mathrm{~V} \cdot \mathrm{cm}^{-1} \cdot \mathrm{Oe}^{-1}$ out of resonance at $100 \mathrm{~Hz}$, at 6 Oe was demonstrated. These are the highest $\mathrm{ME}$ coefficients in thin film composites reported ever [62].

(x) $\mathrm{BaTiO}_{3}-(1-\mathrm{x}) \mathrm{Co}_{0.7} \mathrm{Fe}_{2.3} \mathrm{O}_{4} \mathrm{ME}$ nanocomposite ceramics with $\mathrm{x}=0.0,0.25,0.50,0.75,1.00$ were successfully designed and fabricated by sol-gel route by Gaikwad et al. [63]. The resulting ME voltage coefficient, $7.7 \mathrm{mV} \cdot \mathrm{cm}^{-1} \cdot \mathrm{Oe}^{-1}$, makes the material suitable for storage device applications.

By using an unsymmetrical bi-layered Metglas $/ \mathrm{Pb}(\mathrm{Zr}, \mathrm{Ti}) \mathrm{O}_{3} \mathrm{ME}$ composites with multi-push pull configuration, Gao et al. [64] obtained a ME voltage coefficient of $250 \mathrm{~V} \cdot \mathrm{cm}^{-1} \cdot \mathrm{Oe}^{-1}$, on which the resonance frequency can be varied from $70 \mathrm{~Hz}$ to $220 \mathrm{~Hz}$, allowing the authors to develop a magnetic field energy harvesters capable of harvesting energy generated by electronic instruments working on a $60 \mathrm{~Hz}$ AC power supply. Using the same materials, Palneedi et al. [65] deposited PZT on a Metglas foil by a granule spray in vacuum process at room temperature, followed by its localized annealing with radiation from a continuous-wave $560 \mathrm{~nm}$ ytterbium fiber laser. As a result, a colossal off-resonance 
ME voltage coefficient $\left(3 \mathrm{~V} \cdot \mathrm{cm}^{-1} \cdot \mathrm{Oe}^{-1}\right.$ - two orders of magnitude larger than previously reported) output from the PZT/Metglas film-composites was achieved.

Keeping the focus on PZT-based materials and changing the magnetostrictive phase to Terfenol-D, Wen et al. [66] reported a ME coefficient of $10 \mathrm{~V} \cdot \mathrm{cm}^{-} 1 \cdot \mathrm{Oe}^{-1}$ suitable for broadband magnetic field sensors. A lead-free ME laminate composite consisting of thickness-polarized piezoelectric Mn-doped $\mathrm{Na}_{0.5} \mathrm{Bi}_{0.5} \mathrm{TiO}_{3}-\mathrm{BaTiO}_{3}$ single crystal and length-magnetized magnetostrictive $\mathrm{Tb}_{0.3} \mathrm{Dy}_{0.7} \mathrm{Fe}_{1.92}$ alloy (L-T mode) have been fabricated by Wang et al. [67], exhibiting a linear ME response of $1.32 \mathrm{~V} \cdot \mathrm{cm}^{-1 \cdot} \mathrm{Oe}^{-1}$ that opened up the possibility for environment-friendly magnetic sensors.

Amorín et al. [68] reported an in-depth study of the local material properties across the interfaces of $0.36 \mathrm{BiScO}_{3}-0.64 \mathrm{PbTiO}_{3} / \mathrm{NiFe}_{2} \mathrm{O}_{4}$ multilayer ceramic composites, processed by spark plasma sintering of nanocrystalline powders being obtained a ME voltage coefficient of $100 \mathrm{mV} \cdot \mathrm{cm}^{-1} \cdot \mathrm{Oe}^{-1}$.

Polycrystalline $\mathrm{Pt}$ thin films of different thicknesses $(0-75 \mathrm{~nm})$ were introduced using magnetron sputtering in PZT (400 nm in thickness))/Pt/Ni multiferroic film heterostructures by Feng et al. [69], aiming an optimized transfer efficiency of magnetostrictive strain from the bottom $\mathrm{Ni}$ foil to the top PZT film. It was obtained a direct ME voltage coefficient of $772 \mathrm{mV} \cdot \mathrm{cm}^{-1} \cdot \mathrm{Oe}^{-1}$. ME composite ceramics of $\mathrm{NiFe}_{2} \mathrm{O}_{4}$ and PZT were also synthesized by a simple in situ processing based on a sol-gel method followed by a conventional sintering, exibiting a ME voltage coefficient of $28.5 \mathrm{~V} \cdot \mathrm{cm}^{-1} \mathrm{Oe}^{-1}$ [70]. A strong and anisotropic ME effect $\left(1 \mathrm{~V} \cdot \mathrm{cm}^{-1 \cdot} \mathrm{Oe}^{-1}\right)$ was obtained in composites of magnetostrictive $\mathrm{Ni}$ and solid-state grown lead-free piezoelectric $82 \mathrm{BaTiO}_{3}-10 \mathrm{BaZrO}_{3}-8 \mathrm{CaTiO}_{3}$ single crystals [71] enabling the realization of customized ME effects in composites. The reported ceramic-based ME materials, as well as their production technique are summarized on Figure 10, being observed that the ME voltage coefficient can assume a broad range of values, from less than $10 \mathrm{mV} \cdot \mathrm{cm}^{-1} \cdot \mathrm{Oe}^{-1}$ until almost $1 \mathrm{kV} \cdot \mathrm{cm}^{-1 \cdot} \mathrm{Oe}^{-1}$.

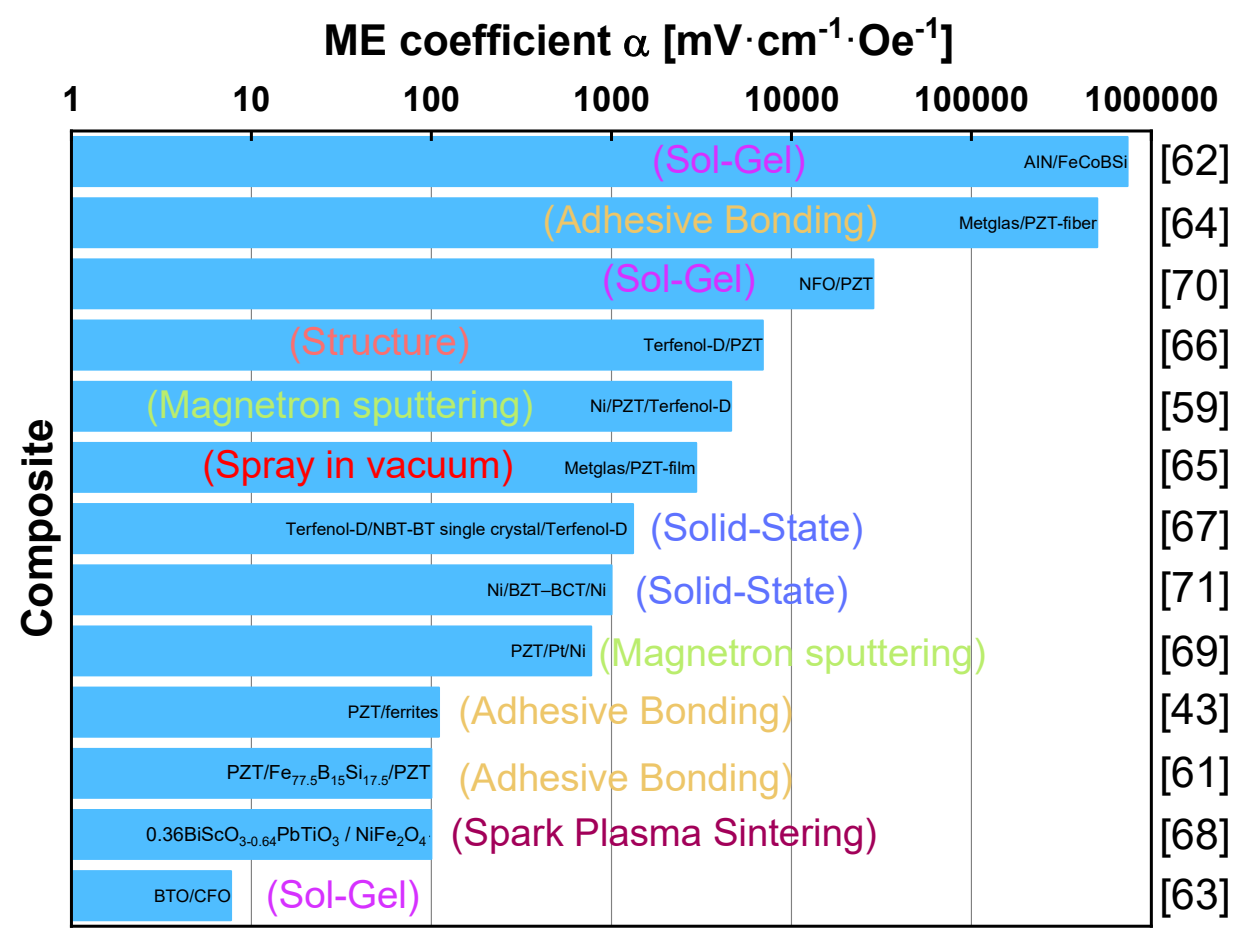

Figure 10. Some representative ceramic-based ME materials together with the ME coefficients, processing techniques, and main application areas.

\section{Polymer-Based Magnetoelectrics}

Despite the polymer-based ME materials presenting a lower ME coefficient, they are increasingly being used as they allow overcoming some of the above-mentioned problems associated to the 
ceramic-based ME materials such as fragility, rigidity and high-cost and also due to their facile, scalable and low-temperature manufacturing methods. The capability to be fabricated in a diversity of forms and shapes, their printability and, in some situations, their biocompatibility are also taken to important advantages $[10,72]$. Among the different methods that are reported for polymer-based ME nanocomposite films development, solution casting is among the most used one [73].

Andrade et al. [74] demonstrated that the introduction of $\mathrm{Gd}_{5}\left(\mathrm{Si}_{2.4} \mathrm{Ge}\right)_{1.6}(\mathrm{GSG})$ into an electroactive matrix (PVDF) gives rise to a ME coupling and a multicaloric effect. A large ME response of $2.2 \mathrm{~V} \cdot \mathrm{cm}^{-1 \cdot} \mathrm{Oe}^{-1}\left(\mathrm{H}_{\mathrm{DC}}=5 \mathrm{kOe}\right.$ at $\left.305 \mathrm{~K}\right)$ was observed for $12 \mathrm{wt}$ \% of filler concentration. It was concluded that the ME effect in PVDF/GSG composites is a result of the elastic cooperation between magnetostrictive and piezoelectric components behavior with a contribution from a thermal mediation arising from the components magnetocaloric and pyroelectric features.

Polyurethane (PU) has been also used as polymeric matrix. Guyomar et al. [75] prepared particulate polymer composites by solution casting, consisting of $\mathrm{PU} /$ Terfenol-D, $\mathrm{PU} / \mathrm{Fe}_{3} \mathrm{O}_{4}$ and $\mathrm{PU} /$ Nickel. It was concluded that whatever the filler type (Terfenol- $\mathrm{D}, \mathrm{Fe}_{3} \mathrm{O}_{4}$ or Nickel), the micro composites show a ME response and that the magnetostrictive property of the material does not have a direct influence on the ME effect since ME sensitivity is DC field independent and the ME polarization coefficient $\alpha_{\mathrm{p}}$ show close values in ac fields for all types of polymer fillers (Table 1).

Table 1. Magnetoelectric coefficient values of polyurethane based composite films [76].

\begin{tabular}{cccc}
\hline $\boldsymbol{\alpha}_{\boldsymbol{p}}\left(\mathbf{C} / \mathbf{m}^{2} \cdot \mathbf{O e}\right)$ & PU $\mathbf{2} \% \mathbf{N i}$ & PU $\mathbf{2} \% \mathbf{F e}_{3} \mathbf{O}_{\mathbf{4}}$ & PU 2\%TeD \\
\hline$f_{1}=120 \mathrm{~Hz}$ & $6.2 \times 10^{-11}$ & $1.2 \times 10^{-10}$ & $4 \times 10^{-11}$ \\
$f_{2}=1 \mathrm{kHz}$ & $5.3 \times 10^{-10}$ & $6.15 \times 10^{-10}$ & $2.2 \times 10^{-10}$ \\
\hline
\end{tabular}

Recently, polymer-based ionic liquid composites, in the form of films and fibers have been processed, with focus on the influence of the cations or anions on the physical-chemical properties of the composites and in the improvement of electromechanical actuators [76]. Correia et al. [77] demonstrated the concept of exploring magnetic ionic liquids (MIL), such as $\left[\mathrm{C}_{4} \mathrm{mim}\right]\left[\mathrm{FeCl}_{4}\right]$, in polymer-based $\mathrm{ME}$ nanocomposites, suitable for low-field magnetic sensing devices (Figure 11).

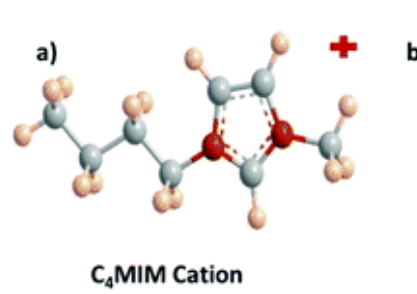

d)

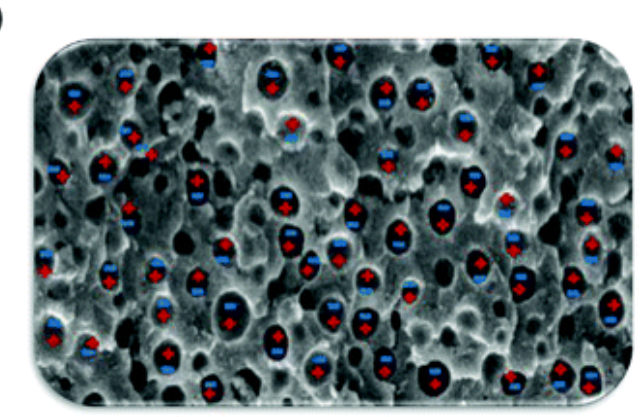

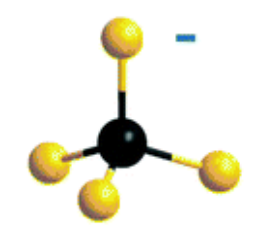

$\mathrm{FeCl}_{4}$ Anion

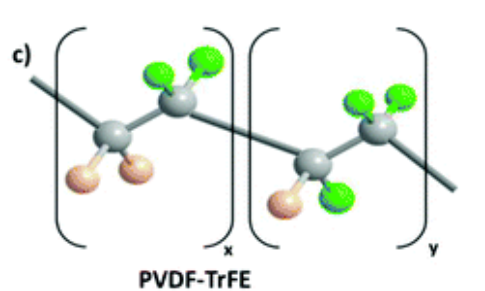

e)

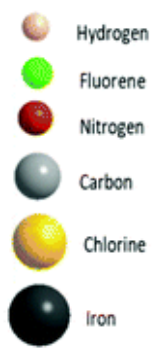

Iron

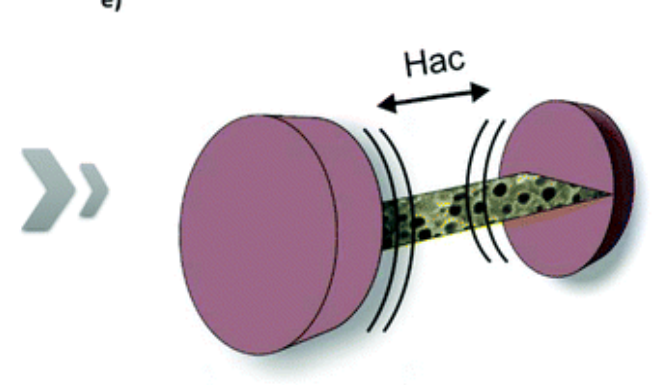

Figure 11. The MI nanocomposite and experimental set-up for the measurement of the MI effect. (a) Schematic representation of the $\left[\mathrm{C}_{4} \mathrm{mim}\right]+$ cation. (b) Schematic representation of the $\left[\mathrm{FeCl}_{4}\right]$-anion.

(c) Illustration of the P(VDF-TrFE) monomer structure. (d) Profile chart of the MI composite.

(e) Schematic view of the system for MI voltage measurement. Reproduced with permission from [77]. 
The novel MI nanocomposites produced using P(VDF-TrFE) as the passive porous material, showed a giant $\alpha_{\mathrm{ME}}$ coefficients of $10 \mathrm{~V} \cdot \mathrm{cm}^{-1} \cdot \mathrm{Oe}^{-1}$, at a $\mathrm{H}_{\mathrm{AC}}$ intensity of $2 \mathrm{Oe}$ and $\mathrm{H}_{\mathrm{AC}}$ frequency of $10 \mathrm{kHz}$. This response includes a magnetically triggered ionic/charge movement within the porous structure of the polymer, being this a novel phenomenon never experimentally observed or explored in ME composites before.

Noticeably, enhanced values of $\alpha_{\mathrm{ME}}$ have been found in laminated composites consisting of magnetostrictive and piezoelectric layers glued together, since the beginning of the millennium [78]. This type ME composites show ME voltage coefficients of up to $1000 \times$ larger than any other type of ME materials, leading to the designation of giant ME effect. The elastic coupling in ferromagnetic/ferroelectric polymer-based laminates was first reported by Mori in 2002 [79]. From the different polymers used for the development of ME laminates, polyvinylidene fluoride (PVDF) and its copolymers are the most popular ones; nevertheless, it is possible also to find several works with diamines [80].

Concerning to the magnetostrictive component of laminates, there are three materials responsible for almost $90 \%$ of the work carried out on polymer-based ME laminates: Metglas, VITROVAC, and Terfenol-D [81]. Tri and bi-layered ME flexible composite structures of variable geometries and sizes with magnetostrictive VITROVAC and piezoelectric PVDF layers were fabricated through direct bonding. Silva et al. [82] reported the effect of the bonding layer type and piezoelectric layer thickness on the ME response of layered (PVDF)/epoxy/Vitrovac composites (Figure 12).

a)

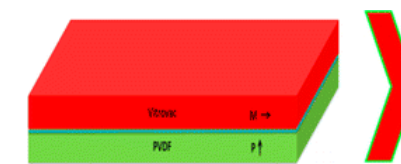

Epoxy optimization

PVDF thickness optimizatiol

b)

Theoretical evaluation
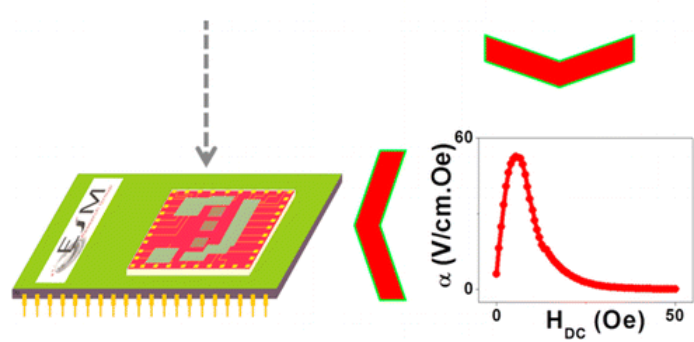

c)

Figure 12. The schematic representation of the Vitrovac/Epoxy/PVDF composite (a); optimization process (b) and ME response (c) pave the way for its incorporation into technological applications such as magnetic sensors (d). Reproduced with permission from [82].

An increase of the ME voltage coefficient from $45 \mathrm{~V} \cdot \mathrm{cm}^{-1} \cdot \mathrm{Oe}^{-1}$ to $53 \mathrm{~V} \cdot \mathrm{cm}^{-1} \cdot \mathrm{Oe}^{-1}$ was verified with increasing PVDF thickness from $28 \mu \mathrm{m}$ to $110 \mu \mathrm{m}$ and a reduction of the ME voltage coefficient from $53 \mathrm{~V} \cdot \mathrm{cm}^{-1} \cdot \mathrm{Oe}^{-1}$ to $6 \mathrm{~V} \cdot \mathrm{cm}^{-1} \cdot \mathrm{Oe}^{-1}$ with increasing epoxy Young modulus from $2.7 \times 10^{8} \mathrm{~Pa}$ to $9.0 \times 10^{9} \mathrm{~Pa}$ [82]. Jing et al. [83], prepared, by a hot-pressing method, a polymer-matrix composite of (CFO/CNT/PVDF)/P(VDF-TrFE)/(CFO/CNT/PVDF) with a P(VDF-TrFE) layer sandwiched between two layers of $\mathrm{CFO} / \mathrm{CNT} / \mathrm{PVDF}$ mixtures. The $\alpha_{\mathrm{ME}}$ of the polymer-matrix composites increases with increasing volume fraction of CFO particles. The self-biased and peak value $\alpha_{\mathrm{ME}}$ of the composites reach up to $16.7 \mathrm{mV} \cdot \mathrm{cm}^{-1} \cdot \mathrm{Oe}^{-1}$ and $25.8 \mathrm{mV} \cdot \mathrm{cm}^{-1} \cdot \mathrm{Oe}^{-1}$, respectively, at approximately $\pm 1000 \mathrm{Oe}$, at low frequency of $1 \mathrm{kHz}$.

PVDF is considered as the "material of merit" for these applications, however, Zong et al. [84], stated that there is an enormous potential in other polymers to bring significant added-value properties and function to ME composite devices. For this reason, it was reported the development of ME composites based on the natural biopolymer, cellulose. To fabricate cellulose-based ME composites, the authors prepared laminate (bilayer) structures comprising Metglas and cellulose films (Figure 13), enabling two-phase strain coupling for enhanced ME response. 


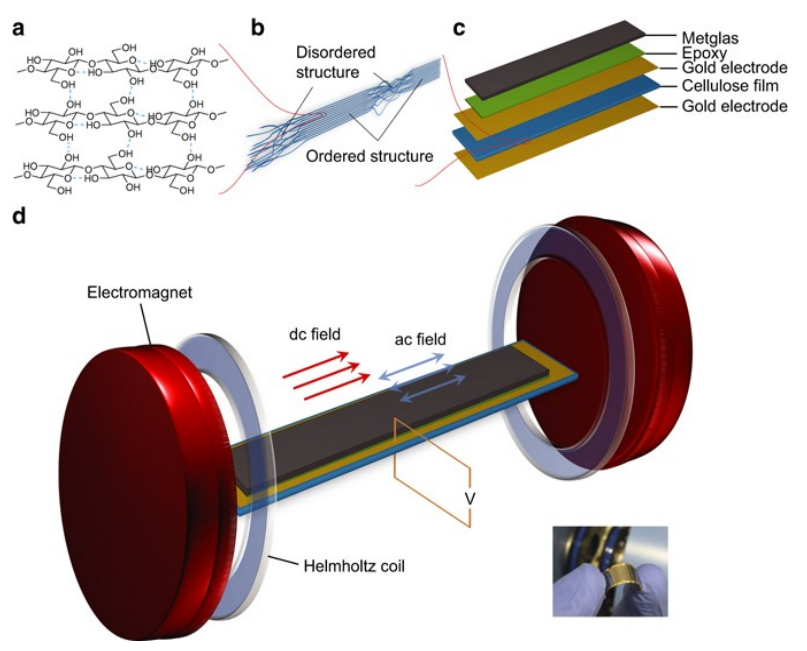

Figure 13. (a) The scheme of cellulose crystal II; (b) Illustration of cellulose fibril alignment at the cross-section of cellulose film; (c) Schematic of cellulose-based ME laminate structure; (d) Schematic view of the bulk system for ME voltage measurement. Reproduced with permission from [84].

The cellulose-based ME laminate composite produced a substantial ME coefficient of approximately $1.41 \mathrm{~V} \cdot \mathrm{cm}^{-1} \cdot \mathrm{Oe}^{-1}$, at $\mathrm{H}_{\mathrm{DC}}=4.2 \mathrm{Oe}$ [84]. Although laminated ME materials exhibit a higher (three orders of magnitude) ME response, nanocomposites offer other benefits such as cost effectiveness, high control of the process parameters and scalable production with good reproducibility [85].

Innovatively multifunctional $\mathrm{ME}$ composites of poly(vinylidene fluoride-co-trifluoroethylene) $\mathrm{P}(\mathrm{VDF}-\mathrm{TrFE}) / \mathrm{CoFe}_{2} \mathrm{O}_{4}$ were spray-printed [86], being observed a ME voltage coefficient of $21.2 \mathrm{mV} \cdot \mathrm{cm}^{-1} \cdot \mathrm{Oe}^{-1}$, demonstrating the suitability of these materials for cost-effective and large-scale sensor/actuator applications, namely in aerospace, automotive and recreational products.

ME material were also printed by the screen-printing technique [87] by using P(VDF-TrFE as the piezoelectric phase and poly(vinylidene fluoride)(PVDF- $\mathrm{CoFe}_{2} \mathrm{O}_{4}$ ) as the magnetostrictive phase. The reported ME coefficient was $164 \mathrm{mV} \cdot \mathrm{cm}^{-1} \cdot \mathrm{Oe}^{-1}$ suitable for printed electronics, sensors, actuators, and energy harvesters. The work of Martins et al. [88] also focused on the development of a new type of $\mathrm{ME}$ polymer nanocomposites that exhibited a tailored $\mathrm{ME}$ response at room temperature. The authors developed multiferroic nanocomposites based on three different ferrite nanoparticles, $\mathrm{Zn}_{0.2} \mathrm{Mn}_{0.8} \mathrm{Fe}_{2} \mathrm{O}_{4}$ (ZMFO), $\mathrm{CoFe}_{2} \mathrm{O}_{4}(\mathrm{CFO})$ and $\mathrm{Fe}_{3} \mathrm{O}_{4}(\mathrm{FO})$, dispersed in $\mathrm{P}(\mathrm{VDF}-\mathrm{TrFE})$ matrix. ME results of the nanocomposite films with $10 \mathrm{wt}$ \% ferrite content revealed that the ME induced voltage increases with increasing DC magnetic field until a maximum of $6.5 \mathrm{mV} \cdot \mathrm{cm}^{-1} \cdot \mathrm{Oe}^{-1}$, at an optimum magnetic field of $0.26 \mathrm{~T}$, and $0.8 \mathrm{mV} \cdot \mathrm{cm}^{-1} \cdot \mathrm{Oe}^{-1}$, at an optimum magnetic field of $0.15 \mathrm{~T}$, for the $\mathrm{P}(\mathrm{VDF}-\mathrm{TrFE}) / \mathrm{CFO}$ and $\mathrm{P}(\mathrm{VDF}-\mathrm{TrFE}) / \mathrm{FO}$ composites, respectively.

By producing $\mathrm{P}(\mathrm{VDF}-\mathrm{TrFE}) / \mathrm{BaTiO}_{3}$ composites through a solvent casting method, Mayeen et al. [89] reported a ME voltage coefficient of $18.2 \mathrm{mV} \cdot \mathrm{cm}^{-1} \cdot \mathrm{Oe}^{-1}$ suitable for energy storage, harvesting, energy conversion. By depositing a PVDF solution of a Metglas substrate a ME voltage coefficient of 686 $\mathrm{mV} \cdot \mathrm{cm}^{-1} \cdot \mathrm{Oe}^{-1}$ was obtained, that was used on a magnetic sensor with a sensitivity of $503.3 \mathrm{~V} \cdot \mathrm{T}^{-1}$ and correlation coefficient of 0.9994 [90].

Polymer-based ME materials were also tested for magnetic sensing by Reis et al. [91] who bonded a PVDF layer to a Metglas foil. The observed ME voltage response $\left(30 \mathrm{~V} \cdot \mathrm{cm}^{-1 \cdot} \mathrm{Oe}^{-1}\right)$ allied to a charge amplifier, an AC-RMS converter and a microcontroller with an on-chip analog-to-digital converter allowed $1.5 \mathrm{~V} \cdot \mathrm{Oe}^{-1}\left(15 \mathrm{kV} \cdot \mathrm{T}^{-1}\right)$ sensitivity and a $70 \mathrm{nT}$ resolution, very attractive for applications such as Earth magnetic field sensing, digital compasses, navigation, and magnetic field anomaly detectors, among others. The same author also fabricated and characterized a high-performance polymer-based ME DC magnetic field AC/DC sensing device composed of PVDF and $\mathrm{Fe}_{61.6} \mathrm{Co}_{16.4} \mathrm{Si}_{10.8} \mathrm{~B}_{11.2}$. The sensing device exhibited a ME response $\left(250 \mathrm{~V} \cdot \mathrm{cm}^{-1} \cdot \mathrm{Oe}^{-1}\right)$, accuracy $(99 \%$ for both AC and DC sensors), 
linearity ( $92 \%$ for the DC sensor and 99\% for the AC sensor) and reproducibility (99\% for both sensors) indicate the suitability of the sensor for applications [92].

Using other copolymer of PVDF-poly(vinylidene fluoride-hexafluoropropylene) [P(VDF-HFP)], Lu et al. [93] glued the polymer to a Metglas ribbon (2605SA1), being reported a $12 \mathrm{~V} \mathrm{~cm}^{-1} \cdot \mathrm{Oe}^{-1} \mathrm{ME}$ voltage coefficient that followed linear relationship with the in situ poling electric field.

Using a dual approach (by experiments and modeling) Belouadah et al. [94], studied the phase switching phenomenon in ME laminate polymer composites, reporting the ME effect $\left(\approx 900 \mathrm{MV} \cdot \mathrm{cm}^{-1} \cdot \mathrm{Oe}^{-1}\right)$ observed in bi- and trilayered polymers consisting of PVDF and polyurethane (PU) filled with magnetically hard magnetite $\mathrm{Fe}_{3} \mathrm{O}_{4}$ or Terfenol-D magnetostrictive material. A good agreement between the simulated results and experimental data was obtained and it was found that phase switching characteristics are mainly influenced by the ME losses induced by magnetostriction losses. In particular, nanocomposites allow advanced production techniques, such as additive manufacturing, facilitating technology transfer to the industry and integration into devices [77]. Consequently, laminated composites present higher ME responses at lower magnetic fields whereas nanocomposites are characterized by improved production features. Therefore, the future of ME materials is closely related to the optimization of the ME response on nanocomposites or with the introduction of new effects to meet higher ME performances for a wide range of applications [73].

The reported polymer-based ME materials, as well as their production techniques are summarized on Figure 14, being observed that the ME voltage coefficient can assume a broad range of values, from less than $10 \mathrm{mV} \cdot \mathrm{cm}^{-1} \cdot \mathrm{Oe}^{-1}$ up to almost $250 \mathrm{~V} \cdot \mathrm{cm}^{-1} \cdot \mathrm{Oe}^{-1}$.

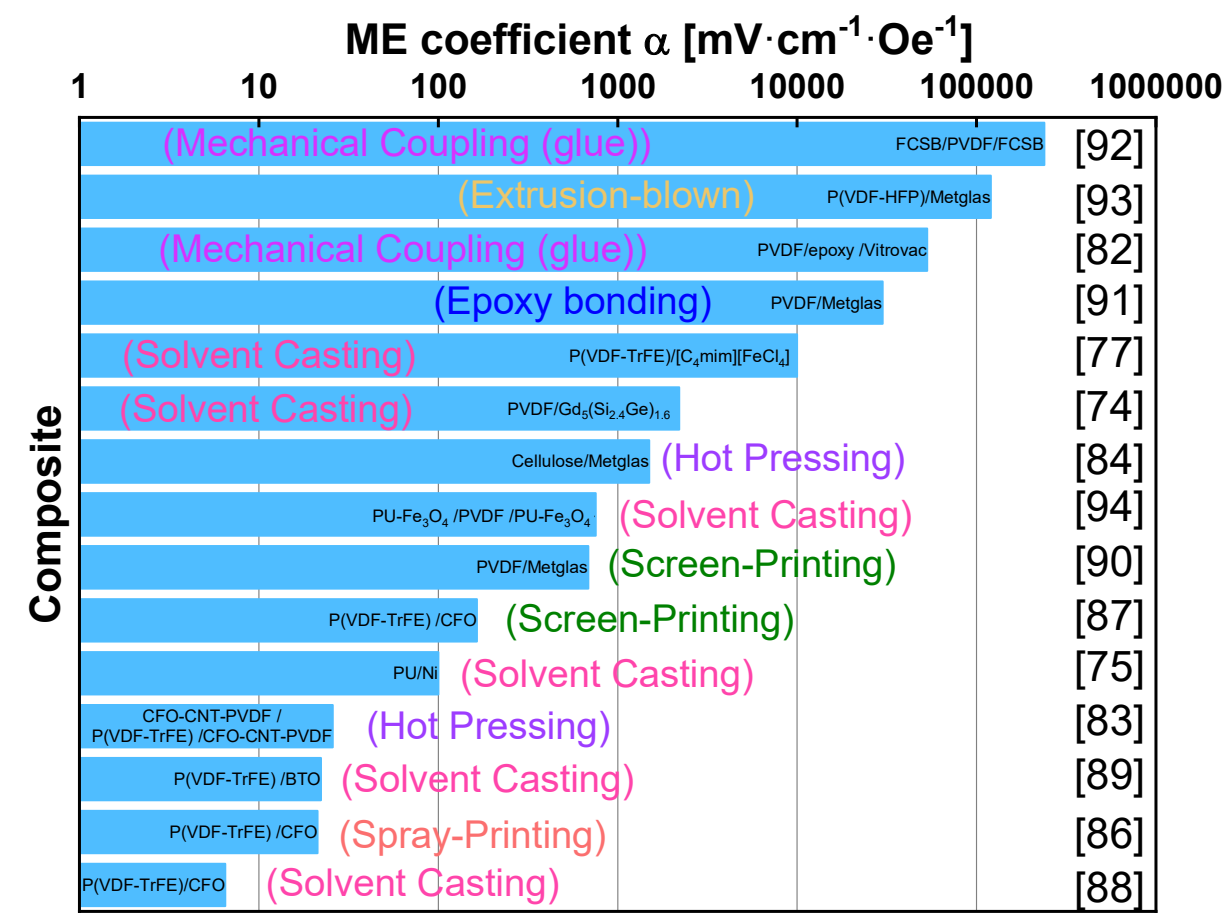

Figure 14. Some representative polymer-based ME materials, and their respective ME voltage coefficient.

\section{Applications in the 4.0 Context}

In IoT, devices are wireless connected, through communications protocols, to the internet. Each device has a unique identifier that allows them to communicate with each other by sending or receiving data. The main concepts of an IoT system are the dynamic nature, the self-adapting ability, the self-configuration and the self-powered capacity [95]. ME devices have the capability to sense and harvest the ambient magnetic energy based on direct magnetic coupling. On the other hand, filters, tunable resonators and memories can capitalize the converse ME coupling, where the electric field 
controls the permeability, the spintronics or the magnetization [53]. Additionally, when compared to the piezoelectric materials, ME materials can harvest/sense magnetic energy and are more suitable for constitution of technical devices for wireless communication. Einstein has stated that any energy is coupled with gravitation. As a result, the ME materials can also support the acoustic wave propagation coupled with some gravitational phenomena. The original theory was developed in 2016 [96] and the possible hot application is the development of instant interplanetary communication [97].

Regarding energy generators Ghosh et al. [98], developed a flexible rollable magneto-mechanoelectric nanogenerator (MMENG) for wireless IoT to capture parasitic magnetic noise native from electrical power transmission systems. The device was produced by combining magnetostrictive $\mathrm{NiFe}_{2} \mathrm{O}_{4}$ nanoparticles, with approximately $9 \mathrm{~nm}$ of diameter and $\mathrm{P}(\mathrm{VDF}-\mathrm{TrFE})$ polymer and a ME coefficient of $11.43 \mathrm{mV} \cdot \mathrm{cm}^{-1} \cdot \mathrm{Oe}^{-1}$ was achieved. The device placed on a magnetic field of $1.7 \times 10^{-3} \mathrm{~T}$ at $50 \mathrm{~Hz}$ from the power cord of a kettle, produce a peak-to-peak voltage $\left(\mathrm{V}_{\mathrm{PP}}\right)$ of $1.4 \mathrm{~V}$ and an output power density of $0.05 \mu \mathrm{W} \cdot \mathrm{cm}^{-3}$. The signal was transmitted to a smartphone for demonstration of position monitoring for the integration of self-power sensors on implantable biomedical devices and human health monitoring sensory systems [98].

Yang et al. [99], reported a vibration energy harvesting multi-cantilever beam. The system is composed by a ME transducer by sandwiching one layer of PMNT between two layers of Terfenol-D. For the experimental setup, the authors used a vibration shaker connected to a function generator and an accelerometer mounted on the shaker. The output voltage was measured by a digital oscilloscope. The shaker acceleration was set to $0.2 \mathrm{~g}$ and the frequency swiped from 15 to $40 \mathrm{~Hz}$. This system was capable of producing a power density of $0.2-0.56 \mathrm{~mW} \cdot \mathrm{cm}^{-3}$ under an acceleration of $0.2 \mathrm{~g}$ [99]. A PZT/ Ni unimorph cantilever with a NdFeB magnet as tip mass was developed by Lu et al. [100] for energy harvesting in wireless sensing applications. This harvester has a maximum power density of $270 \mu \mathrm{W} \cdot \mathrm{cm}^{-3}$ at the resonance frequency of $50 \mathrm{~Hz}$. The demonstration showed that the device was capable of harvesting energy from the ambient magnetic energy and powering commercial wireless temperature/humidity sensors [100].

The work on [101] reports on a magnetic proximity sensor combining printed technologies and a polymer-based ME laminate. This ME laminate was produced by direct bonding a commercial polarized PVDF film, with deposited contacts, and magnetostrictive Metglas layers magnetized along the length direction. The sensor was completed by printing a coil by screen printing technique with silver ink, Figure 15. The proposed device creates an AC magnetic field from the coil that is directed to the ME laminate and when a DC magnetic field is present, the sensor reacts with an increase or decrease of the peak-to-peak voltage proportional to the applied DC magnetic field. This sensor presents a resonance frequency of $13.2 \mathrm{kHz}$, and a ME coefficient of $50.2 \mathrm{~V} \cdot \mathrm{cm}^{-1} \cdot \mathrm{Oe}^{-1}$ [101].

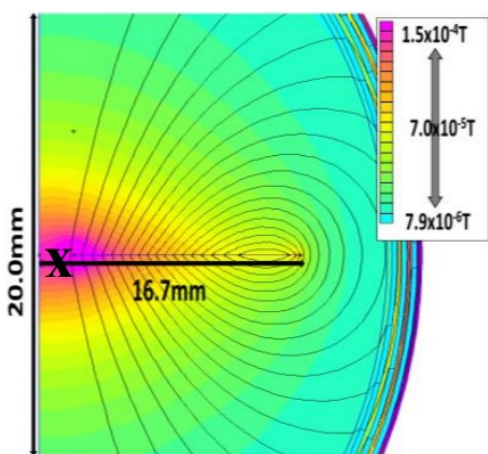

(a)

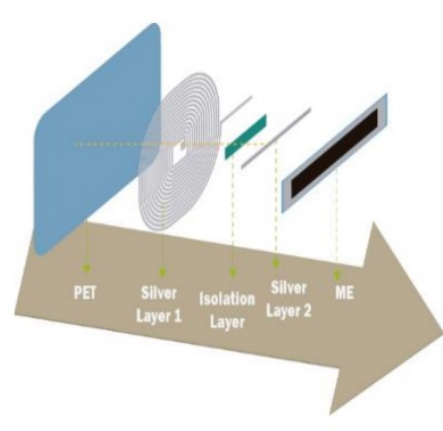

(b)

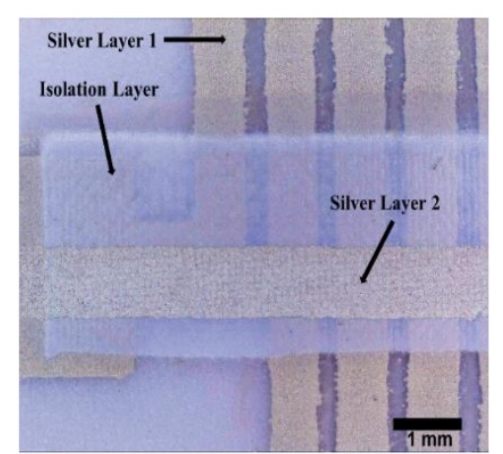

(c)

Figure 15. (a) The theoretical simulation of the AC magnetic field (in T) generated for a printed coil with a width of 750 and $250 \mu \mathrm{m}$ spacing, 15 turns and a current (I) = 0.02 A. (b) Schematic representation of the printing process of the coils. (c) Coil printing detail obtained with a digital microscope. Reproduced with permission from [101]. 
Friedrich et al. [102], developed a magnetic particle mapping (MPM), based on a ME sensor composed by $\mathrm{Fe}_{70.2} \mathrm{Co}_{7.8} \mathrm{Si}_{12} \mathrm{~B}_{10}$ (FeCoSiB) and aluminium nitride fabricated MEMS for the detection for localizing magnetic particles in a medical context. The magnetic particles were biocompatible and were used for diagnostic/treatment of cancer and labelling and tracking cells. The proposed technique detected the nonlinear magnetic response at a magnetic excitation filed on a ME sensor in a freestanding cantilever topology with a low limit detection of $100 \mathrm{pT} /(\mathrm{Hz})^{0.5}$ at $10 \mathrm{~Hz}$ using modulation techniques. The sensor exhibited a bandpass behaviour with a $10 \mathrm{~Hz}$ bandwidth and a resonance frequency of $7.55 \mathrm{kHz}$. With the use of a charge amplifier, the sensor presented a maximum sensitivity $18 \mathrm{kV} / \mathrm{T}$. The MPM can be used as an alternative of more expensive techniques such as magnetic resonance imaging (MRI) or magnetorelaxometry imaging (MRX) [102].

In $2019 \mathrm{Ou}$ et al. [103], developed a $\mathrm{SrFe}_{12} \mathrm{O}_{19} / \mathrm{FeCuNbSiB} / \mathrm{PZT}$ self-biased ME cantilever sensor. The sensor has shown a large output voltage and sensitivity $\left(198.91 \mathrm{mV} \cdot \mathrm{A}^{-1}\right.$ at $\left.50 \mathrm{~Hz}\right)$ without $\mathrm{DC}$ bias magnetic field and is capable of detection steps of $0.01 \mathrm{~A}$. This sensor can be used on the monitoring of power line consumption [103].

Chu et al. [104], reported a ME magnetic field sensor based in the control of the magnetization via an applied electric field with a ME laminate composed by $\mathrm{Pb}\left(\mathrm{Mg}_{1 / 3}-\mathrm{Nb}_{2 / 3}\right) \mathrm{O}_{3}-\mathrm{Pb}(\mathrm{Zr}, \mathrm{Ti}) \mathrm{O}_{3}(\mathrm{PMN}-\mathrm{PZT})$ crystal, poled along the thickness direction and a pickup coil wound around the laminate. This laminate was electrically driven by the contacts deposited on the piezoelectric layer at the frequency of its first-order longitudinal vibration mode, and the induced voltage was captured by the pickup coil based on the law of electromagnetic induction, Figure 16. The ME laminate show a sensitivity of 3400 $\mathrm{V} / \mathrm{T}$, the induced voltage was mainly proportional to the excitation voltage. The sensor also exhibited a limit of detection of $\approx 115 \mathrm{pT}$ at $10 \mathrm{~Hz}$ and $300 \mathrm{pT}$ at $1 \mathrm{~Hz}$, with a power consumption of $0.56 \mathrm{~mW}$ [104].
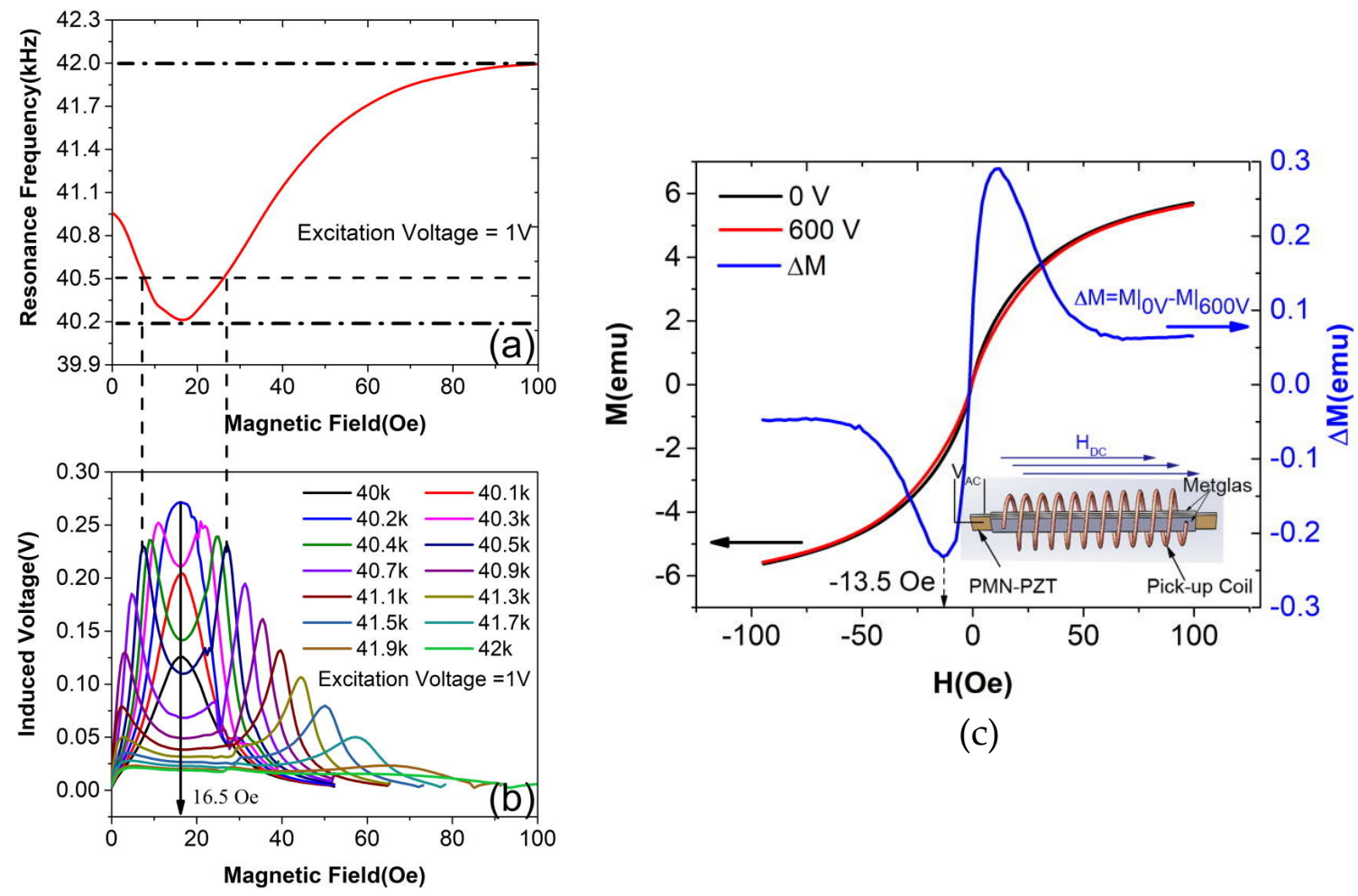

(c)

Figure 16. (a) The resonance frequency of the ME laminate as a function of applied $\mathrm{H}_{\mathrm{DC}}$, (b) The induced voltage as a function of applied HDC and excitation frequency, (c) The M-H loop of the ME laminate with voltages of $0 \mathrm{~V}$ and $600 \mathrm{~V}$ applied to the piezoelectric crystal. $\Delta \mathrm{M}$ as a function of external HDC is also given on the right. The inset shows the schematic of the ME heterostructure. Reproduced with permission from [104]. 
$\mathrm{Xu}$ et al. [105], developed a low frequency transmitter based on the capabilities of the ME resonance sensor. The ME laminate was composed by a piezoelectric layer (PZT-5A) at the core and a magnetostrictive layer on top and bottom (Metglas). This device exhibited higher efficiency compared to current loop antenna of the same size. The proposed device has successfully demonstrated the generation of an $\mathrm{AC}$ magnetic field by driving the piezoelectric phase at the resonance frequency $(30 \mathrm{kHz})$. The device also revealed the capability to act as a receiver antenna [105]. Keeping focus on the antennas, NanoNeuroRFID is an ultra-compact implantable device composed by a ME antenna array that can harvest electromagnetic energy to power the device, sense quasi-static neuronal magnetic fields as small as $200 \mathrm{pT}$ without direct contact to the tissue, communicate with an external transceiver and works from 10 to $100 \mathrm{MHz}$, where tissue loss is small [106]. The ME antenna based on FeGaB/AlN thin film exhibited a sensitivity of $2.475 \mathrm{~Hz} / \mathrm{nT}$ and an ultra-low magnetic noise of $2.36 \mathrm{pT} / \mathrm{Hz}^{1 / 2}$ at $10 \mathrm{~Hz}$. The device is composed by an array of ME antennas for increasing the output voltage [106].

Rupp et al. [107], developed a wireless power receiver (Figure 17a)) for wearables and implantable applications based on a ME laminate composed of PVDF/Metglas with a very small footprint, smaller than $2 \mathrm{~mm}^{3}$. The presented device was able to produce a higher power density when compared to conventional inductive couple coils. The ME device can produce $21.3 \mathrm{~mW} / \mathrm{mm}^{3}$ and $31.3 \mu \mathrm{W} \cdot \mathrm{mm}^{-3}$ under the standards of the Institute of Electrical and Electronics Engineers (IEEE) and the International Commission on Non-Ionizing Radiation Protection (ICNIRP), respectively, with a resonance frequency of $99.3 \mathrm{kHz}$ (Figure 17a)) [107].

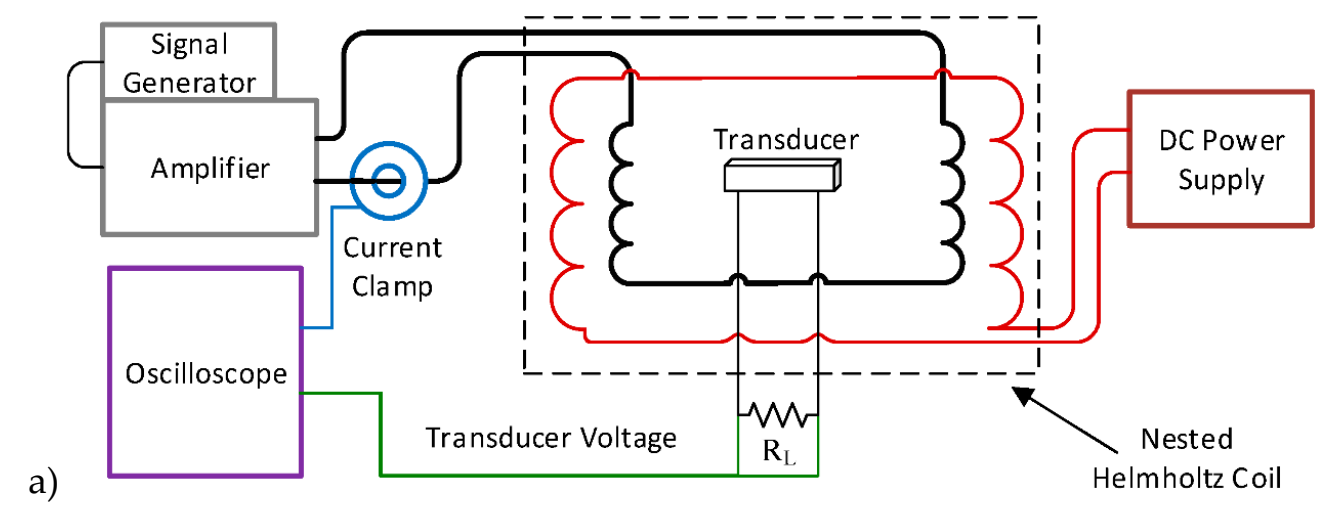

b)

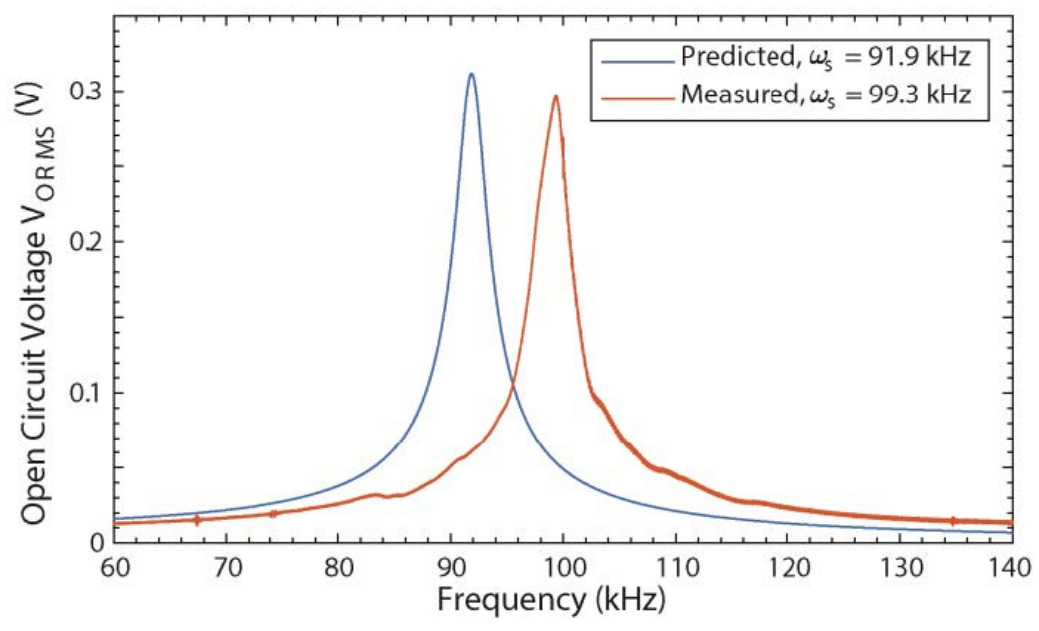

Figure 17. (a) The ME transducer experimental test setup diagram. (b) Metglas-PVDF open circuit voltage vs. frequency. Reproduced with permission from [107]. 
A non-volatile and flexible $\mathrm{ME} \mathrm{SmFeO}_{3} / \mathrm{P}(\mathrm{VDF}-\mathrm{TrFE})$ nanocomposite memory device was introduced by Ahlawat et al. [108]. The nanocomposite film allowed electrically controlled magnetic switching with a ME coefficient of $45 \mathrm{mV} \cdot \mathrm{cm}^{-1} \cdot \mathrm{Oe}^{-1}$ at $1 \mathrm{kOe}$ and $16 \mathrm{mV} \cdot \mathrm{cm}^{-1} \cdot \mathrm{Oe}^{-1}$ at 0 Oe. By applying positive and negative electric fields, the ME coefficient can switch states. The information stored using the ME coefficient shows the key advantage of non-destructive reading of polarization of ferroelectric random-access memories. It was also stated that the voltage for switching can be tuned by varying the magnetic phase fraction [108]. Still in memory devices, Wei et al. [109], reported a giant, stable, tunable and non-volatile converse ME effect in FeAl/PIN-PMN-PT ferromagnetic/ferroelectric heterostructures at room temperature with electrical magnetization modulation that can be used for a four-state memory, with electrical-writing and magnetic-reading. High density information storage can be obtained due to giant electrical modulation of magnetization [109].

Sadeghi et al. [110], reported a ME self-sensing actuator, fabricated by stacking with epoxy and hydrostatic pressure layers of Metglas/PMN-PT/Metglas. This device can work as an actuator and as a sensor. The maximum sensitivity of the actuator at the resonance frequency of $60.7 \mathrm{kHz}$ was of about $5.2 \mathrm{~nm} \cdot \mathrm{mA}^{-1}$ for the actuator and $0.64 \mathrm{mV} \cdot \mathrm{mA}^{-1}$ for the sensor and the operation range of the actuator was from $55 \mathrm{~nm}$ to $386 \mathrm{~nm}$ and the sensor of 58 to $272 \mathrm{mV}$ [110]. The device applications are summarized in Table 2.

Table 2. IoT ME device applications.

\begin{tabular}{ccc}
\hline ME Coupling & Device Type & Ref \\
\hline \multirow{4}{*}{ Direct coupling } & Nanogenerator & {$[98]$} \\
& Energy harvesting multi-cantilever beam & {$[99]$} \\
& For energy harvesting in wireless sensing & {$[100]$} \\
& Magnetic proximity sensor & {$[101]$} \\
& Magnetic particle mapping & {$[102]$} \\
& Self-biased ME cantilever sensor & {$[103]$} \\
& Wireless power receiver & {$[107]$} \\
& Self-sensing actuator & {$[110]$} \\
\hline \multirow{2}{*}{ Converse coupling } & Magnetic field sensor & {$[104]$} \\
& Low frequency transmitter & {$[105]$} \\
& Antenna array & {$[106]$} \\
& Flexible memory & {$[108]$} \\
& Four-state memory & {$[109]$}
\end{tabular}

\section{Challenges and Future Perspectives}

This review has shown that the ME effect, despite having almost lost interest of the scientific community several times, always reappeared with greater vigor, being the technological applications discussed in this work a good example of this regeneration capacity. However, not everything is a bed of roses in this research field.

In one hand, it is essential to pursue new piezomagnetic and piezoelectric materials for achieving higher magnetostrictive and piezoelectric coefficients [111]. In this context, [112] it was shown that the introduction of $\mathrm{CaZrO} 3$ increased electric field-induced strain behavior and stated that, nowadays it is possible to achieve high piezoelectric coefficient $d_{33}$ over $400 \mathrm{pC} / \mathrm{N}$ even in non-textured KNN ceramics, although there still persist some serious challenges for large-scale applications. It was also suggested the creation of a real MPB as in PZT system to solve the reasonably large temperature dependence of piezoelectric properties of KNN-based ceramics, which is full of scientific interest and technical importance. To achieve this, more studies are needed on the phase structure and phase diagram of KNN systems. Still, relatively to KNN-based ceramics, it is pointed as a challenge the fact that alkali elements at A-site in KNN are easily evaporated during sintering. To avoid that it's important the establishment of processing techniques to guarantee reliable mass production and industry scale. 
On the other hand, and although significant improvements have been made to achieve high magnetic field sensitivity in two-phase ferromagnetic/ferroelectric laminate composites, improvements are needed at the levels of: (i) the coupling agent or (ii) the complete removal of the coupling agent. Such pursue for multi-phase ME materials presenting high magnetic field sensitivity, remains a big challenge [111], being the printing technologies and the new ME concepts such as the magnetoionic (MI) effect [77] possible solutions.

With respect to applications of ME sensors in real-world environments, it is often concluded that the magnetic field sensitivity is harmed by contamination of the ME signals by external vibration noise sources and that, therefore, the decrease or even the elimination of the external noise is an essential challenge for the ME sensors [112]. The encapsulation of the materials and the use of resonant frequencies outside the contamination noise range are directions that should be followed.

After the innovative development of low-cost MEMS accelerometers with a reasonable behavior in terms of resolution, sensitivity and noise level [113], it would be interesting to increase the number of studies focusing in the engineering of such sensors in real situations, involving the damping ratio and evaluation/identification of other modal parameters, such as mode shapes.

In the IoT context those sensors should gain another feature: their easy integration and usability. The optimization of ME composite structures, such as flexible ME composites that can be integrated into wearable devices is a point of indispensable improvement, namely in fabricating more usable materials and devices (higher flexibility, optimized roughness and electronic miniaturization) [114].

Looking ahead, the integration of magnetic and piezoelectric nanoparticles, or even ME nanoparticles, offers a new world of opportunities to improve the devices that already exist, or the creation of totally new device concepts. This can be extremely interesting in the biomedical research area, where the interactions between nanomaterials and biological systems can be studied/optimized. Despite being expected that the development and the application of ME materials in biology and biomedicine will be of great interest to the scientific community [115], it is essential to study the parameters that can affect the ME effect (size and shape of individual particle and the environmental conditions), know the impact of the electrostatic and magnetostatic interactions between individual nanoparticles and to find a way to characterize the local ME effect in each nanoparticle. All of these demands are the key to a rational design and optimization of ME nanoparticles for this type of applications.

Recent studies have been devoted to the improvement of point-of-care devices for biomedical diagnostics, such as lab-on-a-chip systems where magnetic nanoparticles can take different functions [116] allowing production of magnetic markers with affinities to conjugate ligands for cells, proteins, or nucleic acids, among others. Bio-friendly ME nanoparticles can detect the magnetically labelled targets, allowing an improvement in detection efficiency. Spatial resolution, relative technical simplicity and tailored biocompatibility are some of the advantages of this technology. Still in the biomedical field, ME composites will also allow the mapping of magnetic fields from smaller magnetic sources (brain) and increase the sensitivity of microfluidic analysis in the context of experiments with biological samples [112].

This time travel through materials, configurations, ME coefficients and applications evidenced that an important progress has been made in understanding chemistry/structure/property relationships of the ME coupling and that ME materials are prepared to promote noteworthy breakthroughs in applications within the IoT context. In order to become a reality, issues related to accuracy, usability, scalability, dynamic production, and connectivity must be systematically addressed.

Author Contributions: Conceptualization, P.M. and S.L.-M.; methodology, P.L. and S.L.-M.; validation, N.P., A.C.L., P.L. and S.L.-M.; formal analysis, N.P., A.C.L., P.L. and S.L.-M.; investigation, N.P., A.C.L., P.L. and S.L.-M.; writing-original draft preparation, N.P., A.C.L. and P.L.; writing-review and editing, P.L. and S.L.-M.; supervision, P.L. and S.L.-M.; funding acquisition, S.L.-M. All authors have read and agreed to the published version of the manuscript. 
Funding: This research was funded by FCT-Fundação para a Ciência e Tecnologia: projects UID/FIS/04650/2019, PTDC/EEI-SII/5582/2014, PTDC/BTM-MAT/28237/2017 and PTDC/EMD-EMD/28159/ 2017 and grants CEECIND/03975/2017, SFRH/BD/132624/2017 and SFRH/BD/131729/2017; the Spanish State Research Agency (AEI) and the European Regional Development Fund (ERFD): project PID2019-106099RB-C43/AEI/10.13039/501100011033; Basque Government Industry and Education Departments: ELKARTEK, HAZITEK and PIBA (PIBA-2018-06) programs.

Acknowledgments: The authors thank the FCT-Fundação para a Ciência e Tecnologia- for financial support in the framework of the Strategic Funding UID/FIS/04650/2019 and under projects PTDC/EEI-SII/5582/2014, PTDC/BTM-MAT/28237/2017 and PTDC/EMD-EMD/28159/2017. P.M., A.C.L. and N.P. also support from FCT (for the contract under the Stimulus of Scientific Employment, Individual Support-2017 Call (CEECIND/03975/2017, for the SFRH/BD/132624/2017 and for the SFRH/BD/131729/2017 grant, respectively). Finally, the authors acknowledge funding by the Spanish State Research Agency (AEI) and the European Regional Development Fund (ERFD) through the project PID2019-106099RB-C43/AEI/10.13039/501100011033.and from the Basque Government Industry and Education Department under the ELKARTEK, HAZITEK and PIBA (PIBA-2018-06) programs, respectively.

Conflicts of Interest: The authors declare no conflict of interest.

\section{References}

1. Eerenstein, W.; Mathur, N.D.; Scott, J.F. Multiferroic and magnetoelectric materials. Nature 2006, 442, 759-765. [CrossRef]

2. Nan, C.-W.; Bichurin, M.; Dong, S.; Viehland, D.; Srinivasan, G. Multiferroic magnetoelectric composites: Historical perspective, status, and future directions. J. Appl. Phys. 2008, 103, 031101. [CrossRef]

3. Röntgen, W.C. Ueber die durch Bewegung eines im homogenen electrischen Felde befindlichen Dielectricums hervorgerufene electrodynamische Kraft. Ann. Phys. 1888, 271, 264-270. [CrossRef]

4. Curie, P.J.J.d.P. Sur la symétrie des phénomènes physiques: Symétrie d'un champ électrique et d'un champ magnétique. J. Phys. 1894, 3, 393-415.

5. Dzyaloshinskii, I.E. On the magneto-electrical effects in antiferromagnets. Soviet Phys. JETP 1960, 10, 628-629.

6. Wang, K.-F.; Liu, J.-M.; Ren, Z. Multiferroicity: The coupling between magnetic and polarization orders. Adv. Phys. 2009, 58, 321-448. [CrossRef]

7. Fiebig, M. Revival of the magnetoelectric effect. J. Phys. D Appl. Phys. 2005, 38, R123-R152. [CrossRef]

8. Van Suchtelen, J. Product properties: A new application of composite materials. Philips Res. Rep. 1972, 2, 28-37.

9. Lu, C.; Wu, M.; Lin, L.; Liu, J.-M. Single-phase multiferroics: New materials, phenomena, and physics. Natl. Sci. Rev. 2019, 6, 653-668. [CrossRef]

10. Palneedi, H.; Annapureddy, V.; Priya, S.; Ryu, J. Status and perspectives of multiferroic magnetelectric composite materials and applications. Actuators 2015, 5, 9. [CrossRef]

11. Fernández, C.L.; Pereira, N.; Martins, P.; Lanceros-Méndez, S. Theoretical design of high-performance polymer-based magnetoelectric of fibrilar structures. Compos. Sci. Technol. 2018, 155, 126-136. [CrossRef]

12. Tong, C. Introduction to Materials for Advanced Energy Systems; Springer: Berlin, Germany, 2019.

13. Shi, Z.; Zhang, J.; Li, J.-F.; Nan, C.-W.; Ma, J. Magnetoelectric properties of multiferroic composites with pseudo 1-3 type structure. MRS Proc. 2006, 966, 124108. [CrossRef]

14. Lanceros-Méndez, S.; Martins, P. Magnetoelectric Polymer-Based Composites: Fundamentals and Applications; John Wiley \& Sons: Weinheim, Germany, 2017.

15. Longo, F.; Nicoletti, L.; Padovano, A. Smart operators in industry 4.0: A human-centered approach to enhance operators' capabilities and competencies within the new smart factory context. Comput. Ind. Eng. 2017, 113, 144-159. [CrossRef]

16. Gil, K.; Gil, J.; Cruz, B.; Ramirez, A.; Medina, M.; Torres, J. Experimental set up of a magnetoelectric measuring system operating at different temperatures. In Proceedings of the Journal of Physics: Conference Series, Bucaramanga, Colombia, 4-9 May 2015; IOP Publishing: Bristol, UK, 2016; Volume 687, p. 12090.

17. Aceto, G.; Persico, V.; Pescapé, A. Industry 4.0 and health: Internet of things, big data, and cloud computing for healthcare 4.0. J. Ind. Inf. Integr. 2020, 18, 100129. [CrossRef]

18. Dalenogare, L.S.; Benitez, G.B.; Ayala, N.F.; Frank, A.G. The expected contribution of Industry 4.0 technologies for industrial performance. Int. J. Prod. Econ. 2018, 204, 383-394. [CrossRef] 
19. Beier, G.; Ullrich, A.; Niehoff, S.; Reißig, M.; Habich, M. Industry 4.0: How it is defined from a sociotechnical perspective and how much sustainability it includes-A literature review. J. Clean. Prod. 2020, 259, 120856. [CrossRef]

20. Luo, L.; Sun, L.; Long, Y.; Wang, X.; Li, Q.; Liang, K.; Zhao, J.; Yan, W.; Sun, Q.; Su, J.; et al. Multiferroic properties of aurivillius structure Bi4SmFeTi3O15 thin films. J. Mater. Sci. Mater. Electron. 2019, 30, 9945-9954. [CrossRef]

21. Shalini, K.; Pappachan, S.; Mayeen, A.; Kalarikkal, N.; Giridharan, N.V. Strengthened magnetoelectric multiferroic response in (K0.5Na0.5[Nb1-xFex/2Mnx/2]O3) ceramics. Mater. Lett. 2020, 261, 126988. [CrossRef]

22. Casey, R. Solid state chemistry and its applications. Chem. Aust. 2015, 2015, 28.

23. Pikula, T.; Dzik, J.; Guzdek, P.; Kowalczyk, M.; Siedliska, K.; Jartych, E. Magnetic and magnetoelectric properties of Bi0.5Nd0.5FeO3 ceramics. Ceram. Int. 2020, 46, 1804-1809. [CrossRef]

24. Dabas, S.; Kumar, M.; Chaudhary, P.; Shankar, S.; Roy, S.; Thakur, O.P. Structural, energy storage analysis and enhanced magnetoelectric coupling in Mn modified multiferroic BiFeO3. J. Electron. Mater. 2019, 48, 5785-5796. [CrossRef]

25. Kumari, M.; Diestra, D.G.B.; Katiyar, R.; Shah, J.; Kotnala, R.; Chatterjee, R. Observation of strong magnetoelectric coupling and ferromagnetism at room temperature in Fe substituted ferroelectric BaZr0.05Ti0.95O3 thin films. J. Appl. Phys. 2017, 121, 034101. [CrossRef]

26. Paul, J.; Bhardwaj, S.; Sharma, K.; Kotnala, R.K.; Kumar, R. Room temperature multiferroic behaviour and magnetoelectric coupling in Sm/Fe modified Bi4Ti3O12 ceramics synthesized by solid state reaction method. J. Alloy. Compd. 2015, 634, 58-64. [CrossRef]

27. Liu, R.; Pan, L.; Peng, S.; Qin, L.; Bi, J.; Wu, J.; Wu, H.; Ye, Z.-G. The magnetoelectric effect in a cubic ferrimagnetic spinel LiFe5O8 with high coupling temperature. J. Mater. Chem. C 2019, 7, 1999-2004. [CrossRef]

28. Pan, L.; Yuan, Q.; Liao, Z.; Qin, L.; Bi, J.; Gao, D.; Wu, J.; Wu, H.; Ye, Z.-G. Superior room-temperature magnetic field-dependent magnetoelectric effect in BiFeO3-based multiferroic. J. Alloy. Compd. 2018, 762, 184-189. [CrossRef]

29. De, J.R.; Rahman, R.A.U.; Sundarakannan, B.; Ramaswamy, M. Room temperature multiferroicity and magnetoelectric coupling in Na-deficient sodium bismuth titanate. Appl. Phys. Lett. 2019, 114, 062902. [CrossRef]

30. Xue, F.; Tian, Y.; Jian, G.; Li, W.; Tang, L.; Guo, P. Ferroelectromagnetic pseudocubic BiFeO3-LaFeO3-PbFeO2.5: Leakage current, dielectric, and multiferroic properties at room temperature. Ceram. Int. 2020, 46, 930-936. [CrossRef]

31. Lakshmi, S.D.; Banu, I.S. Tailoring the multiferroic properties of BiFeO 3 by co-doping Er at Bi site with aliovalent Nb, Mn and Mo at Fe site. Int. J. Appl. Ceram. Technol. 2019, 16, 1622-1631. [CrossRef]

32. Brinker, C.J.; Scherer, G.W. Sol-Gel Science: The Physics and Chemistry of Sol-Gel Processing; Academic Press: London, UK, 2013.

33. Hench, L.L.; West, J.K. The sol-gel process. Chem. Rev. 1990, 90, 33-72. [CrossRef]

34. Zhao, H.; Kimura, H.; Cheng, Z.; Osada, M.; Wang, J.; Wang, X.; Dou, S.X.; Liu, Y.; Yu, J.; Matsumoto, T.; et al. Large magnetoelectric coupling in magnetically short-range ordered Bi5Ti3FeO15 film. Sci. Rep. 2014, 4, 5255. [CrossRef]

35. Eason, R. Pulsed Laser Deposition of Thin Films: Applications-Led Growth of Functional Materials; John Wiley \& Sons: Hoboken, NJ, USA, 2007.

36. Yang, S.C.; Kumar, A.; Petkov, V.; Priya, S. Room-temperature magnetoelectric coupling in single-phase BaTiO 3-BiFeO3 system. J. Appl. Phys. 2013, 113, 144101. [CrossRef]

37. Wu, L.; Gao, Y.; Ma, J. Recent progress in multiferroic materials. Sci. China Ser. E Technol. Sci. 2015, 58, 2207-2209. [CrossRef]

38. Yan, Y.; Priya, S. Multiferroic magnetoelectric composites/hybrids. In Hybrid and Hierarchical Composite Materials; Kim, C.-S., Randow, C., Sano, T., Eds.; Springer International Publishing: Cham, Switzerland, 2015; pp. 95-160. [CrossRef]

39. Xie, S.; Ma, F.; Liu, Y.; Li, J.-Y. Multiferroic CoFe2O4-Pb(Zr0.52Ti0.48)O3 core-shell nanofibers and their magnetoelectric coupling. Nanoscale 2011, 3, 3152. [CrossRef] 
40. Zhu, Q.; Xie, Y.; Zhang, J.; Liu, Y.; Zhan, Q.-F.; Miao, H.; Xie, S. Multiferroic CoFe2O4-BiFeO3 core-shell nanofibers and their nanoscale magnetoelectric coupling. J. Mater. Res. 2014, 29, 657-664. [CrossRef]

41. Hu, J.M.; Cheng, L.Q.; Nan, C.W. Multiferroic heterostructures integrating ferroelectric and magnetic materials. Adv. Mater. 2016, 28, 15. [CrossRef]

42. Rani, J.; Kushwaha, V.K.; Kolte, J.; Tomy, C. Structural, dielectric and magnetoelectric studies of [0.5Ba(Zr0.2Ti0.8)O3-0.5(Ba0.7Ca0.3)TiO3]-Ni0.8Zn0.2Fe2O4 multiferroic composites. J. Alloy. Compd. 2017, 696, 266-275. [CrossRef]

43. Lopatin, S.; Lopatina, I.; Lisnevskaya, I. Magnetoelectric PZT/ferrite composite material. Ferroelectrics 1994, 162, 63-68. [CrossRef]

44. Conde, J.; Muralt, P. Characterization of sol-gel $\mathrm{Pb}(\mathrm{Zr} 0.53 \mathrm{Ti0.47)} \mathrm{O} 3$ in thin film bulk acoustic resonators. IEEE Trans. Ultrason. Ferroelectr. Freq. Control. 2008, 55, 1373-1379. [CrossRef]

45. Shrout, T.R.; Zhang, S. Lead-free piezoelectric ceramics: Alternatives for PZT? J. Electroceramics 2007, 19, 113-126. [CrossRef]

46. Hong, C.-H.; Kim, H.-P.; Choi, B.-Y.; Han, H.-S.; Son, J.S.; Ahn, C.W.; Jo, W. Lead-free piezoceramics-Where to move on? J. Mater. 2016, 2, 1-24. [CrossRef]

47. Kularatne, R.S.; Kim, H.; Boothby, J.M.; Ware, T.H. Liquid crystal elastomer actuators: Synthesis, alignment, and applications. J. Polym. Sci. Part B Polym. Phys. 2017, 55, 395-411. [CrossRef]

48. Ma, J.; Hu, J.; Li, Z.; Nan, C.-W. Recent progress in multiferroic magnetoelectric composites: From bulk to thin films. Adv. Mater. 2011, 23, 1062-1087. [CrossRef]

49. Ren, S.Q.; Weng, L.Q.; Song, S.H.; Li, F.; Wan, J.G.; Zeng, M. BaTiO3/CoFe2O4 particulate composites with large high frequency magnetoelectric response. J. Mater. Sci. 2005, 40, 4375-4378. [CrossRef]

50. Jiang, Q.; Ma, J.; Lin, Y.H.; Nan, C.-W.; Shi, Z.; Shen, Z.J. Multiferroic properties of Bi0.87La0.05Tb0.08FeO3 ceramics prepared by spark plasma sintering. Appl. Phys. Lett. 2007, 91, 022914. [CrossRef]

51. Wang, T.; Song, S.; Ma, Q.; Ji, S.-S. Multiferroic properties of BiFeO3 ceramics prepared by spark plasma sintering with sol-gel powders under an oxidizing atmosphere. Ceram. Int. 2019, 45, 2213-2218. [CrossRef]

52. Wang, M.; Wang, T.; Song, S.; Ravi, M.; Liu, R.; Ji, S. Enhanced Multiferroic Properties of $\mathrm{YMnO}_{3} \mathrm{Ceramics}$ Fabricated by Spark Plasma Sintering Along with Low-Temperature Solid-State Reaction. Materials 2017, 10, 474.

53. Cheng, Y.; Peng, B.; Hu, Z.; Zhou, Z.; Liu, M. Recent development and status of magnetoelectric materials and devices. Phys. Lett. A 2018, 382, 3018-3025. [CrossRef]

54. Giap, V.; Groessinger, R.; Tuertelli, R.S. Magnetoelectric properties of CoFe2O4-BaTiO3 core-shell structure composites. In Proceedings of the INTERMAG 2006-IEEE International Magnetics Conference, San Diego, CA, USA, 8-12 May 2006; Institute of Electrical and Electronics Engineers (IEEE): Piscataway, NJ, USA, 2006; p. 830.

55. Yang, H.; Zhang, G.; Lin, Y. Enhanced magnetoelectric properties of the laminated BaTiO3/CoFe2O4 composites. J. Alloy. Compd. 2015, 644, 390-397. [CrossRef]

56. Israel, C.; Mathur, N.; Scott, J.F. A one-cent room-temperature magnetoelectric sensor. Nat. Mater. 2008, 7 , 93-94. [CrossRef]

57. Grössinger, R.; Turtelli, R.S.; Mehmood, N. Materials with high magnetostriction. IOP Conf. Ser. Mater. Sci. Eng. 2014, 60, 012002. [CrossRef]

58. Lopez, J.D.; Dante, A.; Trovão, T.; Mok, R.W.; Carvalho, C.C.; Allil, R.C.D.S.B.; Borghi, F.; Werneck, M.M. Magnetic field sensor based on FBG and magnetostrictive composites of Terfenol-D with oriented magnetic domains. In Proceedings of the Optical Sensors and Sensing Congress (ES, FTS, HISE, Sensors), San Jose, CA, USA, 25 June 2019; p. SW6C.4.

59. Niu, L.; Shi, Y.; Gao, Y. Effect of magnetic-field orientation on dual-peak phenomenon of magnetoelectric coupling in Ni/PZT/Terfenol-D composites. AIP Adv. 2019, 9, 045216. [CrossRef]

60. Pei, Z.; Ju, D. Simulation of the continuous casting and cooling behavior of metallic glasses. Materials 2017, 10, 420. [CrossRef]

61. Amirov, A.; Baraban, I.; Panina, L.; Rodionova, V. Direct magnetoelectric effect in a sandwich structure of pzt and magnetostrictive amorphous microwires. Materials 2020, 13, 916. [CrossRef]

62. Greve, H.; Woltermann, E.; Quenzer, H.-J.; Wagner, B.; Quandt, E. Giant magnetoelectric coefficients in (Fe90Co10)78Si12B10-AlN thin film composites. Appl. Phys. Lett. 2010, 96, 182501. [CrossRef] 
63. Gaikwad, A.S.; Shirsath, S.E.; Wadgane, S.R.; Kadam, R.H.; Shah, J.; Kotnala, R.K.; Kadam, A.B. Magneto-electric coupling and improved dielectric constant of $\mathrm{BaTiO} 3$ and Fe-rich $(\mathrm{Co} 0.7 \mathrm{Fe} 2.3 \mathrm{O} 4)$ ferrite nano-composites. J. Magn. Magn. Mater. 2018, 465, 508-514. [CrossRef]

64. Gao, J.; Hasanyan, D.; Shen, Y.; Wang, Y.; Li, J.; Viehland, D. Giant resonant magnetoelectric effect in bi-layered Metglas/Pb(Zr,Ti)O3 composites. J. Appl. Phys. 2012, 112, 104101. [CrossRef]

65. Palneedi, H.; Maurya, D.; Kim, G.-Y.; Priya, S.; Kang, S.-J.L.; Kim, K.H.; Choi, S.-Y.; Ryu, J. Enhanced off-resonance magnetoelectric response in laser annealed PZT thick film grown on magnetostrictive amorphous metal substrate. Appl. Phys. Lett. 2015, 107, 012904. [CrossRef]

66. Wen, J.-B.; Zhang, J.-J.; Gao, Y. Multiple broadband magnetoelectric response in Terfenol-D/PZT structure. Chin. Phys. B 2018, 27, 27. [CrossRef]

67. Wang, Y.; Zhao, X.; Jiao, J.; Zhang, Q.; Di, W.; Luo, H.; Leung, C.M.; Or, S.W.; Or, D.S.W. Lead-free magnetoelectric laminated composite of Mn-doped Na0.5Bi0.5TiO3-BaTiO3 single crystal and Tb0.3Dy0.7Fe1.92 alloy. J. Alloy. Compd. 2010, 496, L4-L6. [CrossRef]

68. Amorín, H.; Ricote, J.; San-Felipe, I.; Salazar, N.; Del Campo, R.; Barcelay, Y.R.; De La Cruz, J.P.; Ramos, P.; Vila, E.; Castro, A.; et al. Multilayer ceramic magnetoelectric composites with tailored interfaces for enhanced response. ACS Appl. Mater. Interfaces 2017, 9, 39094-39104. [CrossRef]

69. Feng, M.; Wang, J.-J.; Hu, J.-M.; Wang, J.; Ma, J.; Li, H.-B.; Shen, Y.; Lin, Y.-H.; Chen, L.-Q.; Nan, C.-W. Optimizing direct magnetoelectric coupling in $\mathrm{Pb}(\mathrm{Zr}, \mathrm{Ti}) \mathrm{O} 3 / \mathrm{Ni}$ multiferroic film heterostructures. Appl. Phys. Lett. 2015, 106, 072901. [CrossRef]

70. Wu, D.; Gong, W.; Deng, H.; Li, M. Magnetoelectric composite ceramics of nickel ferrite and lead zirconate titanate via in situ processing. J. Phys. D Appl. Phys. 2007, 40, 5002-5005. [CrossRef]

71. Palneedi, H.; Reddy, V.A.; Lee, H.-Y.; Choi, J.-J.; Choi, S.-Y.; Chung, S.-Y.; Kang, S.-J.L.; Ryu, J. Strong and anisotropic magnetoelectricity in composites of magnetostrictive $\mathrm{Ni}$ and solid-state grown lead-free piezoelectric BZT-BCT single crystals. J. Asian Ceram. Soc. 2017, 5, 36-41. [CrossRef]

72. Martins, P.; Larrea, A.; Gonçalves, R.; Botelho, G.; Ramana, E.V.; Mendiratta, S.K.; Sebastian, V.; Lanceros-Mendez, S. Novel anisotropic magnetoelectric effect on $\delta$ - $\mathrm{FeO}(\mathrm{OH}) / \mathrm{P}(\mathrm{VDF}-\mathrm{TrFE})$ multiferroic composites. ACS Appl. Mater. Interfaces 2015, 7, 11224-11229. [CrossRef] [PubMed]

73. Silva, M.; Martins, P.M.; Lanceros-Méndez, S. Types of polymer-based magnetoelectric materials. In Magnetoelectric Polymer-Based Composites; Wiley: Weinheim, Germany, 2017; pp. 45-63.

74. Andrade, V.M.; Amirov, A.; Yusupov, D.; Pimentel, B.; Barroca, N.; Pires, A.L.; Belo, J.H.; Pereira, A.M.; Valente, M.A.; Araújo, J.P.; et al. Multicaloric effect in a multiferroic composite of Gd5(Si,Ge)4 microparticles embedded into a ferroelectric PVDF matrix. Sci. Rep. 2019, 9, 18308. [CrossRef] [PubMed]

75. Guyomar, D.; Matei, D.; Guiffard, B.; Le, Q.; Belouadah, R. Magnetoelectricity in polyurethane films loaded with different magnetic particles. Mater. Lett. 2009, 63, 611-613. [CrossRef]

76. Feng, L.; Wang, K.; Zhang, X.; Sun, X.; Li, C.; Ge, X.; Ma, Y. Flexible solid-state supercapacitors with enhanced performance from hierarchically graphene nanocomposite electrodes and ionic liquid incorporated gel polymer electrolyte. Adv. Funct. Mater. 2017, 28, 1704463. [CrossRef]

77. Correia, D.; Martins, P.; Tariq, M.; Esperança, J.; Lanceros-Méndez, S. Low-field giant magneto-ionic response in polymer-based nanocomposites. Nanoscale 2018, 10, 15747-15754. [CrossRef] [PubMed]

78. Zhay, J. Magnetoelectric Laminated Composites and Devices; Virginia Polytehnic Institute: Blacksburg, VA, USA, 2009.

79. Mori, K.; Wuttig, M. Magnetoelectric coupling in Terfenol-D/polyvinylidenedifluoride composites. Appl. Phys. Lett. 2002, 81, 100-101. [CrossRef]

80. Martins, P.; Lanceros-Méndez, S. Polymer-based magnetoelectric materials: To be or not to be. Appl. Mater. Today 2019, 15, 558-561. [CrossRef]

81. Gutiérrez, J.; Lasheras, A.; Martins, P.; Pereira, N.; Barandiarán, J.M.; Lanceros-Méndez, S. Metallic glass/PVDF magnetoelectric laminates for resonant sensors and actuators: A review. Sensors 2017, 17, 1251. [CrossRef]

82. Silva, M.; Reis, S.; Lehmann, C.; Martins, P.; Lanceros-Méndez, S.; Lasheras, A.; Gutierrez, J.; Barandiaran, J. Optimization of the magnetoelectric response of poly(vinylidene fluoride)/Epoxy/Vitrovac laminates. ACS Appl. Mater. Interfaces 2013, 5, 10912-10919. [CrossRef] [PubMed]

83. Jing, W.; Fang, F. A flexible multiferroic composite with high self-biased magnetoelectric coupling. Compos. Sci. Technol. 2017, 153, 145-150. [CrossRef] 
84. Zong, Y.; Zheng, T.; Martins, P.; Lanceros-Méndez, S.; Yue, Z.; Higgins, M.J. Cellulose-based magnetoelectric composites. Nat. Commun. 2017, 8, 38. [CrossRef]

85. Silva, M.P.; Martins, P.; Lasheras, A.; Gutiérrez, J.; Barandiarán, J.M.; Lanceros-Mendez, S. Size effects on the magnetoelectric response on PVDF/Vitrovac 4040 laminate composites. J. Magn. Magn. Mater. 2015, 377, 29-33. [CrossRef]

86. Martins, P.; Nunes, J.; Oliveira, J.; Peřinka, N.; Lanceros-Mendez, S. Spray-printed magnetoelectric multifunctional composites. Compos. Part B Eng. 2020, 187, 107829. [CrossRef]

87. Lima, A.C.; Pereira, N.; Policia, R.; Ribeiro, C.; Correia, V.M.G.; Lanceros-Méndez, S.; Martins, P. All-printed multilayer materials with improved magnetoelectric response. J. Mater. Chem. C 2019, 7, 5394-5400. [CrossRef]

88. Martins, P.; Kolen'Ko, Y.V.; Rivas, J.; Lanceros-Méndez, S. Tailored magnetic and magnetoelectric responses of polymer-based composites. ACS Appl. Mater. Interfaces 2015, 7, 15017-15022. [CrossRef]

89. Mayeen, A.; Thomas, S.; Rouxel, D.; Philip, J.; Bhowmik, R.N.; Kalarikkal, N.; Jayalakshmy, M.S. Dopamine functionalization of BaTiO3: An effective strategy for the enhancement of electrical, magnetoelectric and thermal properties of BaTiO3-PVDF-TrFE nanocomposites. Dalton Trans. 2018, 47, 2039-2051. [CrossRef]

90. Chlaihawi, A.; Emamian, S.; Narakathu, B.; Ali, M.; Maddipatla, D.; Bazuin, B.; Atashbar, M.Z. Novel screen printed flexible magnetoelectric thin film sensor. Procedia Comput. Sci. 2016, 168, 684-687. [CrossRef]

91. Reis, S.; Castro, N.; Silva, M.; Correia, V.M.G.; Rocha, J.G.; Martins, P.; Lanceros-Méndez, S. Fabrication and characterization of high-performance polymer-based magnetoelectric DC magnetic field sensors devices. IEEE Trans. Ind. Electron. 2017, 64, 4928-4934. [CrossRef]

92. Reis, S.; Silva, M.; Castro, N.; Correia, V.M.G.; Gutiérrez, J.; Lasheras, A.; Lanceros-Méndez, S.; Martins, P. Optimized anisotropic magnetoelectric response of Fe61.6Co16.4Si10.8B11.2/PVDF/Fe61.6Co16.4Si10.8B11.2laminates for AC/DC magnetic field sensing. Smart Mater. Struct. 2016, 25, 55050. [CrossRef]

93. Lu, S.G.; Jin, J.Z.; Zhou, X.; Fang, Z.; Wang, Q.; Zhang, Q.M. Large magnetoelectric coupling coefficient in poly(vinylidene fluoride-hexafluoropropylene)/Metglas laminates. J. Appl. Phys. 2011, 110, 104103. [CrossRef]

94. Belouadah, R.; Guyomar, D.; Guiffard, B.; Zhang, J.-W. Phase switching phenomenon in magnetoelectric laminate polymer composites: Experiments and modeling. Phys. B Condens. Matter 2011, 406, 2821-2826. [CrossRef]

95. Garg, N.; Garg, R. Energy harvesting in IoT devices: A survey. In Proceedings of the 2017 International Conference on Intelligent Sustainable Systems (ICISS), New Delhi, India, 7-8 December 2017; Institute of Electrical and Electronics Engineers (IEEE): Piscataway, NJ, USA, 2017; pp. 127-131.

96. Zakharenko, A.A. On piezogravitocogravitoelectromagnetic shear-horizontal acoustic waves. Can. J. Pure Appl. Sci. 2016, 3, 4011-4028.

97. Zakharenko, A.A. On necessity of development of instant interplanetary telecommunication based on some gravitational phenomena for remote medical diagnostics and treatment. Can. J. Pure Appl. Sci 2016, 2, 4481-4487.

98. Ghosh, S.K.; Roy, K.; Mishra, H.K.; Sahoo, M.R.; Mahanty, B.; Vishwakarma, P.N.; Mandal, D. Rollable magnetoelectric energy harvester as a wireless IoT sensor. ACS Sustain. Chem. Eng. 2019, 8, 864-873. [CrossRef]

99. Yang, J.; Wen, Y.; Li, P.; Dai, X. A magnetoelectric, broadband vibration-powered generator for intelligent sensor systems. Sens. Actuators A Phys. 2011, 168, 358-364. [CrossRef]

100. Chen, J.; Chen, J.; Cheng, Z.; Zhang, S. The PZT/Ni unimorph magnetoelectric energy harvester for wireless sensing applications. Energy Convers. Manag. 2019, 200, 112084. [CrossRef]

101. Pereira, N.; Lima, A.C.; Correia, V.; Peřinka, N.; Lanceros-Méndez, S.; Martins, P. Magnetic proximity sensor based on magnetoelectric composites and printed coils. Materials 2020, 13, 1729. [CrossRef]

102. Friedrich, R.-M.; Zabel, S.; Galka, A.; Lukat, N.; Wagner, J.-M.; Kirchhof, C.; Quandt, E.; Mccord, J.; Selhuber-Unkel, C.; Siniatchkin, M.; et al. Magnetic particle mapping using magnetoelectric sensors as an imaging modality. Sci. Rep. 2019, 9, 1-11. [CrossRef] [PubMed]

103. Ou, Z.; Lu, C.; Yang, A.; Zhou, H.; Cao, Z.; Zhu, R.; Gao, H. Self-biased magnetoelectric current sensor based on $\mathrm{SrFe} 12 \mathrm{O} 19$ /FeCuNbSiB/PZT composite. Sens. Actuators A Phys. 2019, 290, 8-13. [CrossRef] 
104. Chu, Z.; Dong, C.; Tu, C.; Liang, X.; Chen, H.; Sun, C.; Yu, Z.; Dong, S.; Sun, N.X. A low-power and high-sensitivity magnetic field sensor based on converse magnetoelectric effect. Appl. Phys. Lett. 2019, 115, 162901. [CrossRef]

105. Xu, J.; Leung, C.M.; Zhuang, X.; Li, J.; Bhardwaj, S.; Volakis, J.L.; Viehland, D. A Low frequency mechanical transmitter based on magnetoelectric heterostructures operated at their resonance frequency. Sensors 2019, 19, 853. [CrossRef] [PubMed]

106. Zaeimbashi, M.; Lin, H.; Dong, C.; Liang, X.; Nasrollahpour, M.; Chen, H.; Sun, N.; Matyushov, A.; He, Y.; Wang, X.; et al. NanoNeuroRFID: A wireless implantable device based on magnetoelectric antennas. IEEE J. Electromagn. RF Microwaves Med. Boil. 2019, 3, 206-215. [CrossRef]

107. Rupp, T.; Truong, B.D.; Williams, S.; Roundy, S. Magnetoelectric transducer designs for use as wireless power receivers in wearable and implantable applications. Materials 2019, 12, 512. [CrossRef]

108. Ahlawat, A.; Satapathy, S.; Shirolkar, M.M.; Li, J.; Khan, A.A.; Deshmukh, P.; Wang, H.; Choudhary, R.J.; Karnal, A.K. Tunable magnetoelectric nonvolatile memory devices based on SmFeO3/P(VDF-TrFE) nanocomposite films. ACS Appl. Nano Mater. 2018, 1, 3196-3203. [CrossRef]

109. Wei, Y.; Gao, C.; Chen, Z.; Xi, S.; Shao, W.; Zhang, P.; Chen, G.; Li, J. Four-state memory based on a giant and non-volatile converse magnetoelectric effect in FeAl/PIN-PMN-PT structure. Sci. Rep. 2016, 6, 30002. [CrossRef]

110. Sadeghi, M.; Hojjat, Y.; Khodaei, M. Self-sensing feature of the ultrasonic nano-displacement actuator in Metglas/PMN-PT/Metglas magnetoelectric composite. J. Mater. Sci. Mater. Electron. 2019, 31, 740-751. [CrossRef]

111. Wang, Y.; Li, J.; Viehland, D. Magnetoelectrics for magnetic sensor applications: Status, challenges and perspectives. Mater. Today 2014, 17, 269-275. [CrossRef]

112. Murzin, D.; Mapps, D.J.; Levada, K.; Belyaev, V.; Omelyanchik, A.; Panina, L.V.; Rodionova, V. Ultrasensitive magnetic field sensors for biomedical applications. Sensors 2020, 20, 1569. [CrossRef] [PubMed]

113. Ribeiro, R.R.; Lameiras, R. Evaluation of low-cost MEMS accelerometers for SHM: Frequency and damping identification of civil structures. Lat. Am. J. Solids Struct. 2019, 16, 16. [CrossRef]

114. Narita, F.; Fox, M. A Review on piezoelectric, magnetostrictive, and magnetoelectric materials and device technologies for energy harvesting applications. Adv. Eng. Mater. 2017, 20, 1700743. [CrossRef]

115. Faria, M.; Björnmalm, M.; Thurecht, K.J.; Kent, S.J.; Parton, R.G.; Kavallaris, M.; Johnston, A.P.R.; Gooding, J.J.; Corrie, S.R.; Boyd, B.; et al. Minimum information reporting in bio-nano experimental literature. Nat. Nanotechnol. 2018, 13, 777-785. [CrossRef] [PubMed]

116. Lee, H.; Shin, T.-H.; Cheon, J.; Weissleder, R. Recent developments in magnetic diagnostic systems. Chem. Rev. 2015, 115, 10690-10724. [CrossRef]

(C) 2020 by the authors. Licensee MDPI, Basel, Switzerland. This article is an open access article distributed under the terms and conditions of the Creative Commons Attribution (CC BY) license (http://creativecommons.org/licenses/by/4.0/). 